\title{
Recent Developments in Enantioselective Organocatalytic Michael Reactions in Aqueous Media
}

\author{
Hélène Pellissier ${ }^{*}$ \\ Aix Marseille Univ, CNRS, Centrale Marseille, iSm2, Marseille, France
}

\begin{abstract}
Background: This review updates the field of enantioselective organocatalytic Michael reactions performed in aqueous media, covering the literature since the beginning of 2013.
\end{abstract}

Conclusion: From a green chemistry perspective, this review shows that significant efforts have been recently devoted to the development of these reactions in water and in aqueous media.

\section{INTRODUCTION}

Among the various carbon-carbon bond-forming reactions, Michael reactions play a significant role in organic synthesis [1]. In particular, asymmetric versions based on the use of chiral organocatalysts have been extensively developed over the past decade due to the advantageous properties of organocatalysts, such as low toxicity, stability, and convenience in handling [2]. Recently, many efforts have been made to develop these reactions through even more economic and ecological manners by using water as a safe, abundant, cheap, and environmentally benign solvent substitute [3]. In nature, water is the only medium used for biosynthetic reactions to sustain life, which has led chemists to investigate it as a suitable solvent in organic synthesis. Indeed, from a green chemistry perspective, significant efforts have been recently devoted to the development of asymmetric catalytic reactions in aqueous environments, such as enantioselective organocatalytic Michael reactions. The goal of this review is to collect the major developments in enantioselective organocatalytic Michael reactions performed in water or aqueous media published since the beginning of 2013, since this field was most recently reviewed this year by Zhou [4]. It must be noted that a specific review, dedicated to supported organocatalysts for general asymmetric reactions under aqueous conditions, was reported by Guillena in 2015, including only four references of Michael additions dating after 2013 [5]. Moreover, a global non-comprehensive perspective for the use of water in general asymmetric organocatalytic systems was published by Jimeno in 2016, but it included only three examples of Michael reactions published since 2013 [6]. Earlier, this general field was reviewed by several reviews reported by different groups [7]. This review is divided into two parts, dealing successively with enantioselective organocatalytic Michael reactions of nitroalkenes and enantioselective organocatalytic Michael reactions of $\alpha, \beta$-unsaturated carbonyl compounds. Each part is subdivided according to the nature of the organocatalysts employed to promote the reactions.

\section{ENANTIOSELECTIVE ORGANOCATALYTIC MICHAEL REACTIONS OF NITROALKENES}

\subsection{With Proline-Derived Catalysts}

On the basis of the economic and ecological advantages to perform reactions in aqueous media, considerable efforts have been recently devoted to develop efficient water-compatible organocatalysts. The challenge in developing such catalysts arise from their interaction with water, which may disrupt hydrogen bonds and polar interactions between the catalyst and the substrates [3a]. Consequently, for a long time it was presumed that reactions performed in water lead to slow reaction rates and yields [8]. However, a breakthrough occurred with studies reported by Breslow in 1980, demonstrating that Diels-Alder reactions could evolve in water [9]. Later, Sharpless et al. showed that other transformations, defined as "on water" reactions, were greatly accelerated when performed in aqueous suspensions in comparison to the analogue reactions carried out in organic media [10]. In 2006, Hayashi introduced for organocatalytic reactions, a differentiation between the "in water" reactions and the reactions performed in the presence of water [11] In the case of the first ones, the reactants were homogeneously dissolved while the second ones occur in a concentrated organic media, with water being a second phase influencing the stereochemistry of the products. In 2007, Blackmond questioned about the greenness of an organocatalytic reaction performed under aqueous conditions since most of these reactions are performed in the presence of a great excess of reagents or a surfactant/micellar agent [12]. Nevertheless, the simple shift of an organic solvent to water can be included in a green chemistry perspective, especially when the activity of the catalysts is enhanced. In 2006, Barbas et al. reported the first catalytic asymmetric Michael addition of ketones to nitroolefins performed in brine with enantioselectivities of up to $97 \%$ ee by using an amphiphilic protonated proline-derived diamine organocatalyst [13]. The same year, Luo et al. synthesized surfac- 


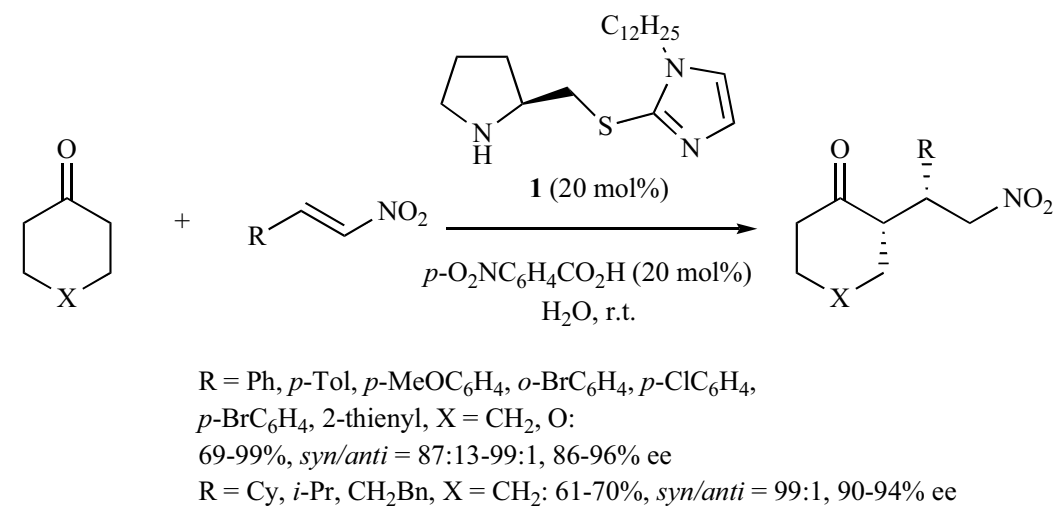

Scheme 1. Michael reaction of cyclic ketones and nitroalkenes with catalyst 1 in the presence of $p-\mathrm{O}_{2} \mathrm{NC}_{6} \mathrm{H}_{4} \mathrm{CO}_{2} \mathrm{H}$ as additive in water.

tant-type organocatalysts to be applied in the same reactions in water, providing enantioselectivities of up to $98 \%$ ee and diastereoselectivities of up to $99 \%$ de [14]. Since these pioneering studies, a range of organocatalysts of different types have been successfully applied to related reactions among which proline-derived ones [15]. For example, Liu et al. reported enantioselective Michael reactions of cyclohexanone andnitroalkenes performed in water at room temperature [16]. As shown in Scheme 1, the conjugate additions were promoted by $20 \mathrm{~mol} \%$ of amphiphilic proline-derived mercapto imidazole catalyst $\mathbf{1}$ in the presence of para-nitrobenzoic acid as an additive, leading to the corresponding Michael products in good to quantitative yields (69-99\%), good to excellent syn-diastereoselectivities (syn/trans $=87: 13-99: 1)$, and high enantioselectivities ( $86-96 \%$ ee). In the case of aliphatic nitroalkenes, the diastereoselectivity was uniformly excellent $($ syn/anti $=99: 1)$ in comparison with that obtained by using aromatic nitroalkenes although the former showed slightly lower reactivity than the latter $(61-70 \%$ yields vs $69-99 \%$ yields). The lowest enantioselectivity ( $86 \%$ ee) was obtained in the reaction of a cyclohexanone exhibiting an oxygen atom $(\mathrm{X}=\mathrm{O})$. Cyclopentanone was also compatible with the catalyst system but with much lower diastereoselectivity of $40 \%$ de although combined with high yield (94\%) and good enantioselectivity $(82 \%$ ee). The emulsion system formed by the amphiphilic organocatalyst was found crucial for achieving both high activity and enantioselectivity.

In 2014, Yan and Zhang developed novel surfactant-type bifunctional thiourea organocatalysts to be applied in comparable reactions [17]. The optimal catalyst 2 was employed at $10 \mathrm{~mol} \%$ of catalyst loading in combination with benzoic acid (10 mol\%) in water at room temperature, allowing the Michael addition of a range of cyclic and acyclic ketones to aromatic nitroalkenes to be achieved in high yields (83-94\%), good to excellent syndiastereoselectivities (syn/anti $=82: 18->99: 1)$ and enantioselectivities $(76-97 \%$ ee). As shown in Scheme 2, the reactivity and stereoselectivities were slightly better in the case of cyclic ketones in comparison with acyclic ones (83-94\% yields vs $83-87 \%$ yields, $82: 18$ to $>99: 1$ (syn/anti) vs up to $96: 4$ (syn/anti), $76-97 \%$ ee vs 77 $78 \%$ ee). In addition to cyclohexanone which provided excellent results (83-94\% yields, $90->98 \%$ de, $78-97 \%$ ee), cyclopentanone and heterocyclic six-membered ketones also led to the corresponding products albeit with slightly lower yields and stereoselectivities ( $85-88 \%$ yields, $64-96 \%$ de, $76-86 \%$ ee). The substrate scope of the reaction was extended to aldehydes which reacted with high yields (86-97\%), syn-diastereoselectivities $(90->98 \%$ de) and enantioselectivities $(90-95 \%$ ee). Later in 2016, Li et al. reported the use of related thiourea bifunctional organocatalyst 3 in the enantioselec- tive Michael addition of cyclohexanone to aromatic nitroalkenes (Scheme 2) [18]. When the reaction was promoted at room temperature with $10 \mathrm{~mol} \%$ of this catalyst in water and in the presence of $10 \mathrm{~mol} \%$ of benzoic acid as additive, it afforded the corresponding Michael products in moderate to high yields (30-92\%), uniformly high syn-diastereoselectivies (96:4->99:1) and enantioselectivities $(94-99 \%$ ee). These excellent stereoselectivities were obtained regardless of the electronic nature of the aromatic substituent $\left(\mathrm{R}^{3}\right)$ of the nitroalkene. On the other hand, the nature of the substituent on the benzene ring of $\mathrm{R}^{3}$ influenced the reaction rate and yield of the reaction. For example, when an electron-donating substituent was introduced to the benzene ring, low to moderate yields were obtained $\left(\mathrm{R}^{3}=p\right.$-Tol, $p-\mathrm{MeOC}_{6} \mathrm{H}_{4}: 30-51 \%$ yield $)$. This catalytic system was not applicable to acyclic ketones which did not react. These reactions were also investigated by Zhao et al. in the presence of another type of organocatalysts, such as $\mathbf{4}$, incorporating pyrrolidine and arylsulfonamide motifs as active catalytic sites and axially unfixed biaryl as a skeleton (Scheme 2) [19]. Performed with $10 \mathrm{~mol} \%$ of this organocatalyst combined with the same quantity of benzoic acid as additive in water, the Michael addition of cyclohexanone to a range of aromatic nitroalkenes led to the corresponding products in high to quantitative yields (80-99\%), high syn-diastereoselectivities (syn/anti $=92: 8->99: 1)$ and good to high enantioselectivities (77-91\% ee). In comparison to aromatic nitroalkenes, aliphatic nitroolefins also yielded the corresponding conjugate products with comparable levels of stereoselectivities (syn/anti $=92: 8->99: 1,89-94 \%$ ee), but with rather low yields (5-24\%). The substrate scope of the process could be extended to an aliphatic ketone $\left(\mathrm{R}^{1}=\mathrm{Et}, \mathrm{R}^{2}=\mathrm{Me}\right)$ which provided by reaction with nitrostyrene the corresponding product in excellent stereoselectivities (syn/anti $=96: 4,89 \%$ ee) albeit with only $26 \%$ yield.

In 2014, Kumar et al. reported the synthesis of a new class of organocatalysts derived from proline and hydroxyimides to be applied in enantioselective nitro-Michael reactions [20]. Among them, pyrrolidine-oxyimide $\mathbf{5}$ was found the most efficient in promoting Michael additions of cyclic ketones, such as cyclohexanone, to aromatic nitroalkenes at room temperature (Scheme 3). Notably, these reactions occurred under additive-free conditions, leading to a range of chiral Michael products in uniformly high yields (8897\%), syn-diastereoselectivities (syn/anti $=91: 9-98: 2)$ and enantioselectivities (84-96\% ee). In addition to cyclohexanone which provided general excellent results irrespective of the nature of the substituent (Ar) beared by the nitroolefin, other cyclic ketones even incorporating heteroatoms were found equally effective in leading to the corresponding products $(86-93 \%$ yields, $82-88 \%$ de, $85-90 \%$ ee). Later in 2016 , the same authors designed another proline- 

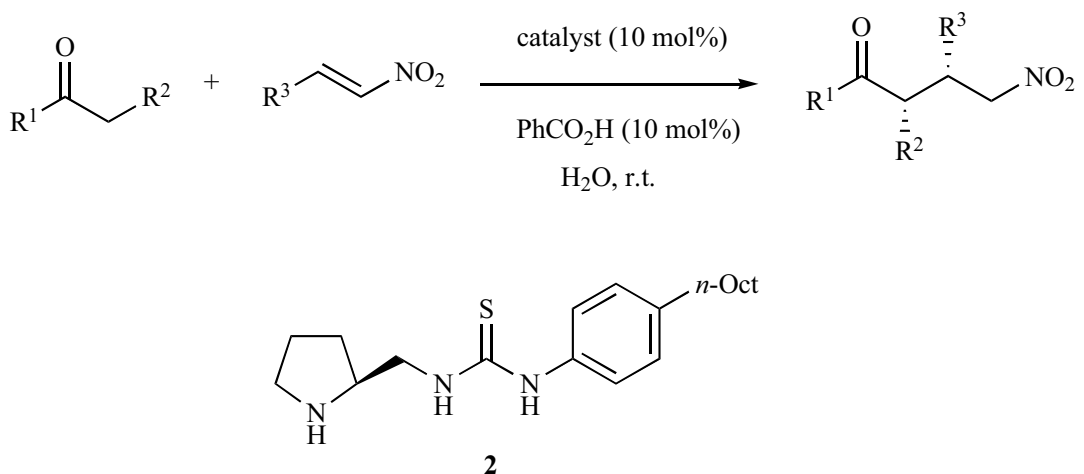

$\mathrm{R}^{1}, \mathrm{R}^{2}=\left(\mathrm{CH}_{2}\right)_{5},\left(\mathrm{CH}_{2}\right)_{2} \mathrm{OCH}_{2},\left(\mathrm{CH}_{2}\right)_{2} \mathrm{SCH}_{2},\left(\mathrm{CH}_{2}\right)_{3}$

$\mathrm{R}^{3}=\mathrm{Ph}, o-\mathrm{O}_{2} \mathrm{NC}_{6} \mathrm{H}_{4}, p-\mathrm{FC}_{6} \mathrm{H}_{4}, p-\mathrm{ClC}_{6} \mathrm{H}_{4}, p-\mathrm{BrC}_{6} \mathrm{H}_{4}, p-\mathrm{Tol}$,

2,4- $\mathrm{Cl}_{2} \mathrm{C}_{6} \mathrm{H}_{3}, p-\mathrm{MeOC}_{6} \mathrm{H}_{4}, 2,4-(\mathrm{MeO})_{2} \mathrm{C}_{6} \mathrm{H}_{3}, 2$-Naph, 2-furyl:

83-94\%, syn/anti $=82: 18->99: 1,76-97 \%$ ee

$\mathrm{R}^{1}=\mathrm{Me}, \mathrm{Et}, \mathrm{R}^{2}=\mathrm{H}, \mathrm{Me}, \mathrm{R}^{3}=\mathrm{Ph}$ :

$83-87 \%$, syn/anti $=$ up to $96: 4,77-78 \%$ ee

$\mathrm{R}^{1}=\mathrm{H}, \mathrm{R}^{2}=n$-Pr, $n$-Bu, $n$-Pent, $n$-Hept, $\mathrm{R}^{3}=\mathrm{Ph}$

$86-97 \%$, syn/anti $=95: 5->99: 1,90-95 \%$ ee

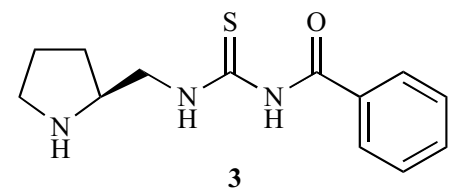

$\mathrm{R}^{1}, \mathrm{R}^{2}=\left(\mathrm{CH}_{2}\right)_{5}, \mathrm{R}^{3}=\mathrm{Ph}, m-\mathrm{O}_{2} \mathrm{NC}_{6} \mathrm{H}_{4}, o-\mathrm{ClC}_{6} \mathrm{H}_{4}, p-\mathrm{ClC}_{6} \mathrm{H}_{4}, p-\mathrm{MeOC}_{6} \mathrm{H}_{4}$, $p$-Tol, 2,4- $\mathrm{Cl}_{2} \mathrm{C}_{6} \mathrm{H}_{3}, p-\mathrm{MeOC}_{6} \mathrm{H}_{4}, p-\mathrm{BrC}_{6} \mathrm{H}_{4}, p-\mathrm{FC}_{6} \mathrm{H}_{4}, 2$-thienyl:

$30-92 \%$, syn/anti $=96: 4->99: 1,94-99 \%$ ee<smiles>Cc1ccc(S(=O)(=O)Nc2ccccc2-c2ccccc2NC[C@@H]2CCCN2)cc1</smiles>

4

$\mathrm{R}^{1}, \mathrm{R}^{2}=\left(\mathrm{CH}_{2}\right)_{5}, \mathrm{R}^{3}=\mathrm{Ph}, o-\mathrm{O}_{2} \mathrm{NC}_{6} \mathrm{H}_{4}, p-\mathrm{FC}_{6} \mathrm{H}_{4}, p-\mathrm{ClC}_{6} \mathrm{H}_{4}, p-\mathrm{BrC}_{6} \mathrm{H}_{4}$, $p$-Tol, $o-\mathrm{O}_{2} \mathrm{NC}_{6} \mathrm{H}_{4}, m-\mathrm{O}_{2} \mathrm{NC}_{6} \mathrm{H}_{4}, p-\mathrm{MeOC}_{6} \mathrm{H}_{4}, 2$-thienyl, 2-furyl: $80-99 \%$, syn/anti $=92: 8$ to $>99: 1,77-91 \%$ ee

$\mathrm{R}^{1}, \mathrm{R}^{2}=\left(\mathrm{CH}_{2}\right)_{5}, \mathrm{R}^{3}=\mathrm{Cy}, i-\operatorname{Pr}$ :

5-24\%, syn/anti $=92: 8->99: 1,89-94 \%$ ee

$\mathrm{R}^{1}=\mathrm{Et}, \mathrm{R}^{2}=\mathrm{Me}, \mathrm{R}^{3}=\mathrm{Ph}:$

$26 \%$, syn/anti $=96: 4,89 \%$ ee

Scheme 2. Michael reaction of ketones and aldehydes with nitroalkenes with catalysts 2-4 in the presence of benzoic acid as additive in water.

derived organocatalyst to be used in these reactions without the presence of additive [21]. As shown in Scheme 3, the use of Lproline-derived oxytriazole 6 in the Michael addition of cyclohexanone to a range of aromatic nitroalkenes in water afforded the corresponding products in high yields (84-95\%), syndiastereoselectivities (syn/anti $=91: 9-96: 4)$ and enantioselectivities (81-95\% ee) irrespective of the nature of the substituent (Ar) of the nitroolefin. Furthermore, the scope was extended to a sixmembered ketone including an oxygen atom, yielding by reaction with nitrostyrene the corresponding product in $86 \%$ yield, syndiastereoselectivity of $82 \%$ de, and enantioselectivity of $83 \%$ ee. Moreover, lower but acceptable levels of yield (78\%) and stereoselectivities $(70 \%$ de, $77 \%$ ee) were obtained in the reaction of cyclopentanone with nitrostyrene. 

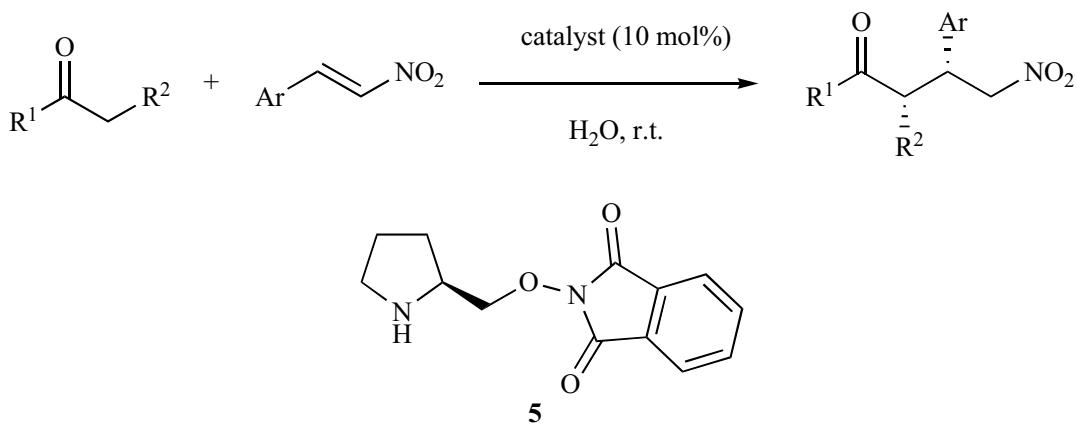

$\mathrm{Ar}=\mathrm{Ph}, m-\mathrm{BrC}_{6} \mathrm{H}_{4}, p-\mathrm{MeOC}_{6} \mathrm{H}_{4}, m-\mathrm{O}_{2} \mathrm{NC}_{6} \mathrm{H}_{4}, p-\mathrm{FC}_{6} \mathrm{H}_{4}, p-\mathrm{Tol}, 2-\mathrm{Cl}-5-\mathrm{O}_{2} \mathrm{NC}_{6} \mathrm{H}_{3}$, $p$ - $\mathrm{O}_{2} \mathrm{NC}_{6} \mathrm{H}_{4}, 2$-pyridyl, 2-furyl, 2-thienyl $\mathrm{R}^{1}, \mathrm{R}^{2}=\left(\mathrm{CH}_{2}\right)_{5}$ :

$88-97 \%$, syn/anti $=91: 9-98: 2,84-96 \%$ ee $\mathrm{Ar}=\mathrm{Ph}, \mathrm{R}^{1}, \mathrm{R}^{2}=\left(\mathrm{CH}_{2}\right)_{4},\left(\mathrm{CH}_{2}\right)_{2} \mathrm{O}\left(\mathrm{CH}_{2}\right)_{2},\left(\mathrm{CH}_{2}\right)_{2} \mathrm{~N}(\mathrm{Me})\left(\mathrm{CH}_{2}\right)_{2}:$ $86-93 \%$, syn/anti $=91: 9-94: 6,85-90 \%$ ee<smiles>c1ccc2c(c1)nnn2OC[C@@H]1CCCN1</smiles>

6

$\mathrm{Ar}=\mathrm{Ph}, m-\mathrm{BrC}_{6} \mathrm{H}_{4}, p-\mathrm{MeOC}_{6} \mathrm{H}_{4}, p-\mathrm{FC}_{6} \mathrm{H}_{4}, m-\mathrm{O}_{2} \mathrm{NC}_{6} \mathrm{H}_{4}, p-\mathrm{Tol}, p-\mathrm{O}_{2} \mathrm{NC}_{6} \mathrm{H}_{4}$, 2-Cl-5- $\mathrm{O}_{2} \mathrm{NC}_{6} \mathrm{H}_{3}, 2,4-(\mathrm{MeO})_{2} \mathrm{C}_{6} \mathrm{H}_{3}$, 2-thienyl, 2-furyl, 2-Naph, 2-pyridyl $\mathrm{R}^{1}, \mathrm{R}^{2}=\left(\mathrm{CH}_{2}\right)_{5}$ : 84-95\%, syn/anti $=91: 9-96: 4,81-95 \%$ ee $\mathrm{Ar}=\mathrm{Ph}, \mathrm{R}^{1}, \mathrm{R}^{2}=\left(\mathrm{CH}_{2}\right)_{4}: 78 \%$, syn/anti $=85: 15,77 \%$ ee $\mathrm{Ar}=\mathrm{Ph}, \mathrm{R}^{1}, \mathrm{R}^{2}=\left(\mathrm{CH}_{2}\right)_{2} \mathrm{O}\left(\mathrm{CH}_{2}\right)_{2}: 86 \%$, syn/anti $=91: 9,83 \%$ ee

Scheme 3. Michael reaction of ketones andaromaticnitroalkenes with catalysts 5-6 without additive in water
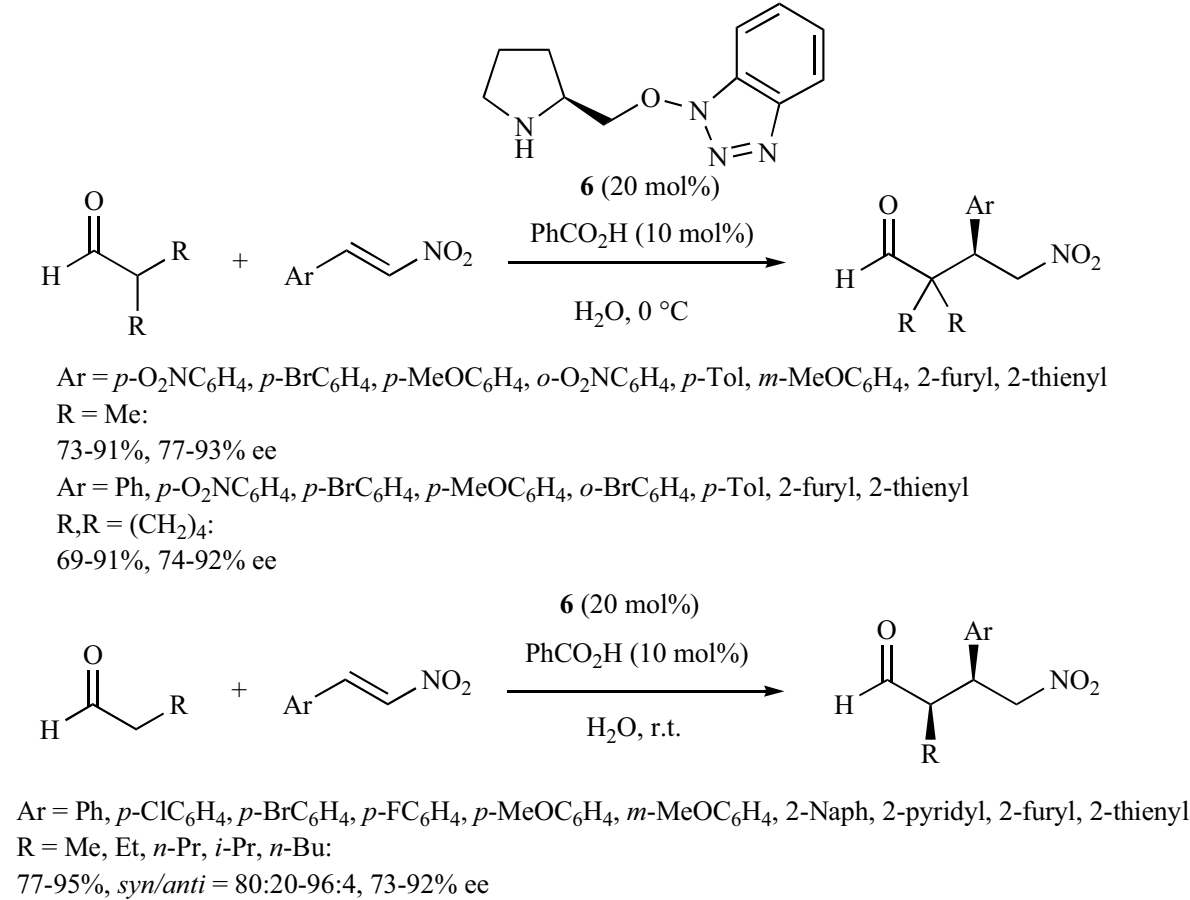

Scheme 4. Michael reactions of aldehydes and aromatic nitroalkenes with catalyst 6 with benzoic acid as additive in water.

In 2017 , the same authors investigated catalyst 6 to promote the enantioselective Michael addition of aldehydes to aromatic nitroalkenes which has been less studied than that involving ketones [22]. As shown in Scheme 4, in this case better results were achieved when the reaction was performed in the presence of 10 mol\% of benzoic acid as additive and $20 \mathrm{~mol} \%$ of catalyst loading. For example, the Michael addition of isobutyraldehyde to a range of aromatic nitroalkenes performed at $0{ }^{\circ} \mathrm{C}$ in water led to the corre- 


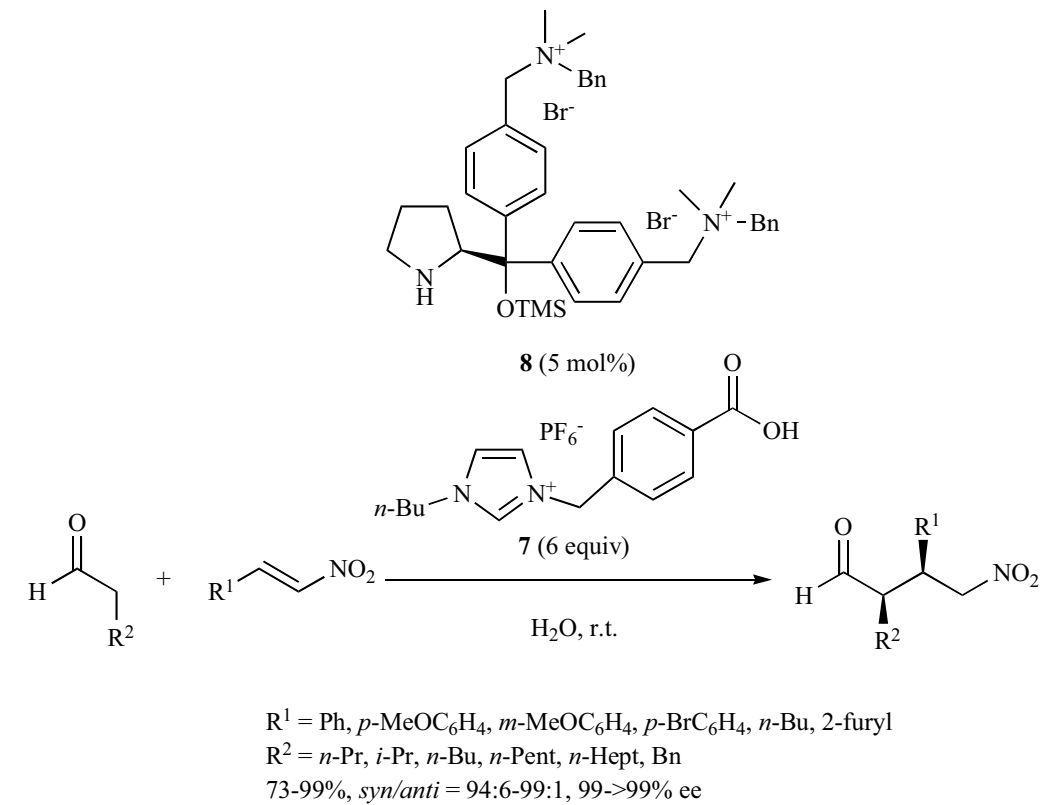

Scheme 5. Michael reaction of aldehydes and nitroalkenes with catalyst $\mathbf{8}$ in the presence of ionic liquid-supported benzoic acid 7 in water.

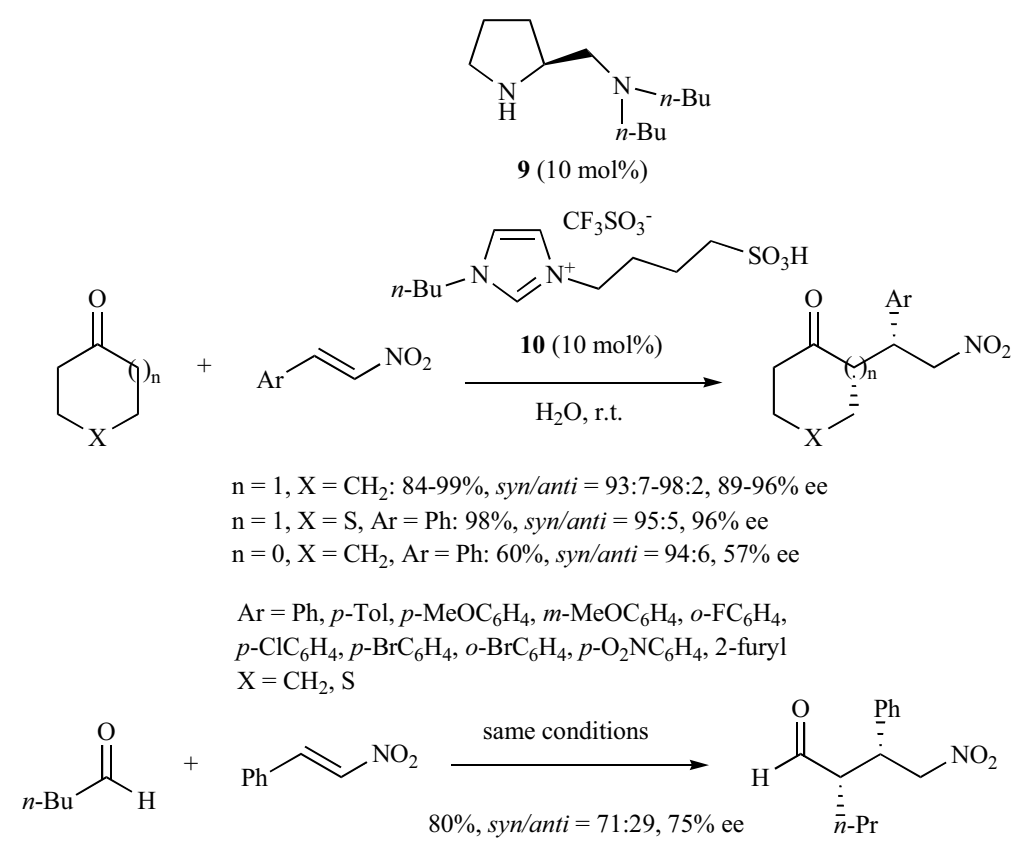

Scheme 6. Michael reactions of cyclic ketones and pentanal with aromatic nitroalkenes with catalyst 9 in the presence of ionic liquid-supported sulfonic acid 10 in water.

sponding products in good to high yields (73-91\%) and enantioselectivities $(77-93 \%$ ee). Comparable results $(69-91 \%$ yields, $74-$ $92 \%$ ee) were also obtained in the reaction of another aldehyde, such as cyclopentanecarboxaldehyde. Furthermore, the substrate scope was extended to linear aldehydes which reacted with various aromatic nitroalkenes at room temperature to give the desired Michael products in high yields (77-95\%), moderate to high syndiastereoselectivities (syn/anti $=80: 20-96: 4)$, and good to high enantioselectivities (73-92\% ee), as shown in Scheme 4. Therefore, reactions involving branched aldehydes provided slightly lower yields (69-91\% vs 77-95\%) than that of linear aldehydes.

In the last decade, many efforts have been devoted to improve the efficiency of organic reactions by using supported and recyclable organocatalysts in aqueous conditions [5, 23]. For example, Headley and $\mathrm{Ni}$ reported the use of an ionic liquid-
Headley and Ni reported the use of an ionic liquid-supported benzoic acid 7 as cocatalyst in the enantioselective Michael addition of aldehydes to nitroalkenes catalyzed by chiral catalyst $\mathbf{8}$ in water [24]. Promoted by this catalyst system at room temperature, the reaction of a series of aliphatic aldehydes and aliphatic as well as aromatic nitroalkenes led to the corresponding products in good to quantitative yields (73-99\%), and both remarkable syndiastereoselectivities (syn/anti $=94: 6-99: 1)$ and enantioselectivities $(\geq 99 \%$ ee), as shown in Scheme 5. Notably, this system could be recycled and reused up to ten times without observing any drop in the enantioselectivity while a noticeable decrease of the yield was found after the sixth run.

In the same context, $\mathrm{Ni}$ et al. developed the synthesis of proline-derived organocatalyst 9 which was combined to ionic liq- 


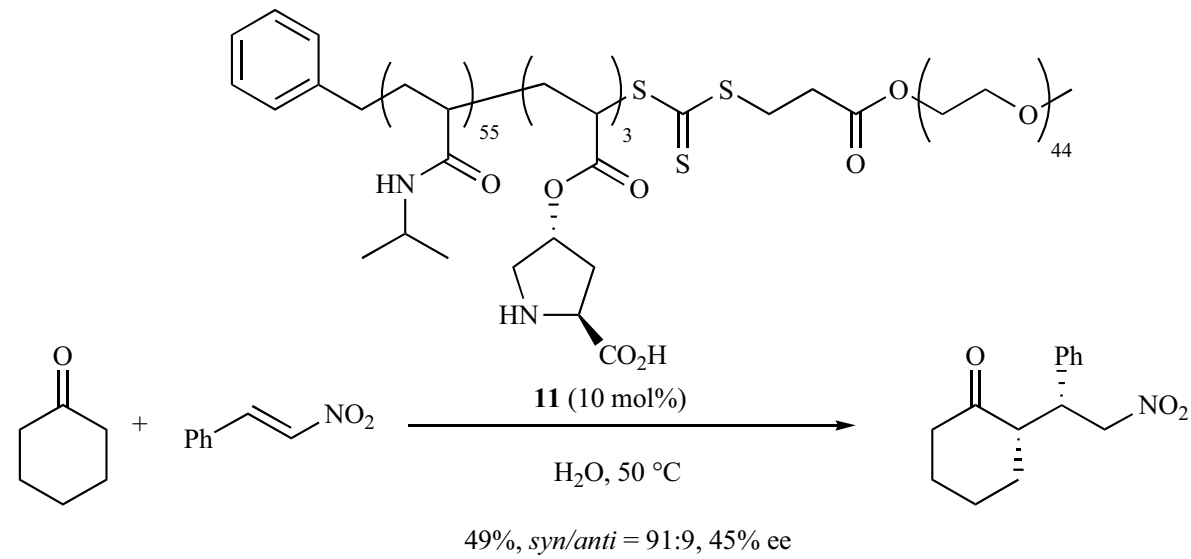

Scheme 7. Michael reaction of cyclohexanone and nitrostyrene with copolymer-supported catalyst 11 in water.

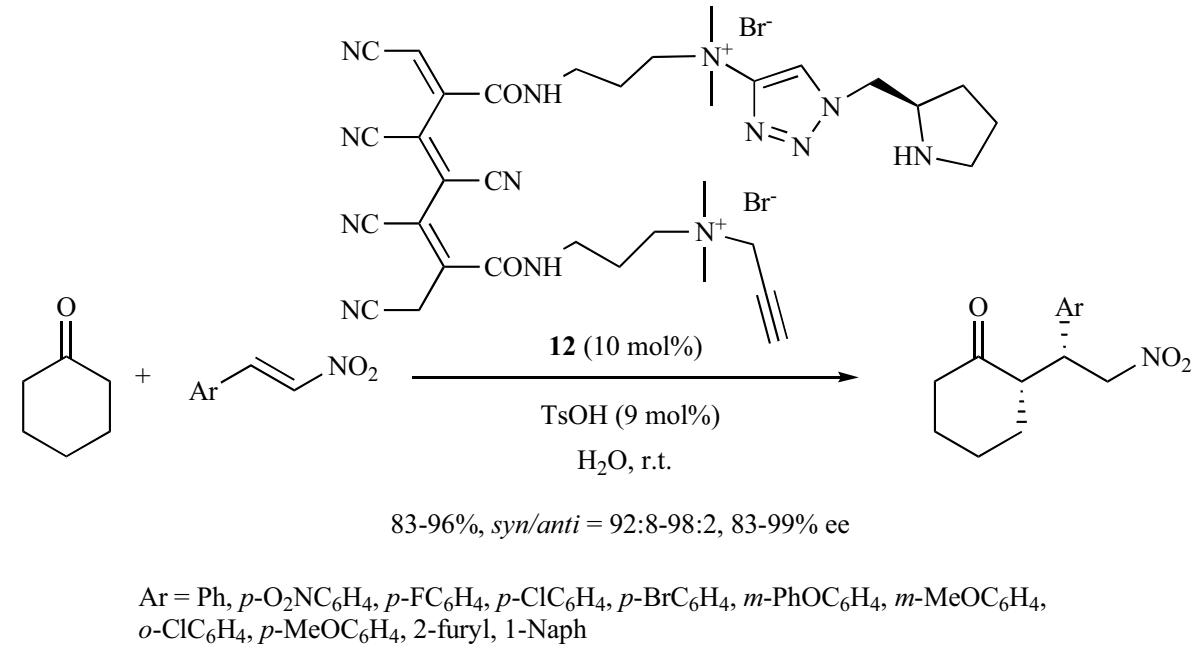

Scheme 8. Michael reaction of cyclohexanone and aromatic nitroalkenes with a polyacrylonitrile-supported catalyst $\mathbf{1 2}$ in water.

uid-supported sulfonic acid $\mathbf{1 0}$ to catalyze in water at room temperature the Michael addition of cyclohexanone to aromatic nitroalkenes to give the desired products in high to quantitative yields $(84-99 \%)$, high syn-diastereoselectivities $(s y n / a n t i=93: 7-98: 2)$ and excellent enantioselectivities (89-96\% ee), as shown in Scheme 6 [25]. The scope of this simple methodology was extended to a sixmembered ketone including a sulfur atom $(X=S)$ which yielded by reaction with nitrostyrene the corresponding $\gamma$-nitrocarbonyl compound in excellent yield (98\%), with both high syn-diastereo- and enantioselectivities (syn/anti $=95: 5,96 \%$ ee, respectively). However, when cyclopentanone was employed as substrate, only moderate yield $(60 \%)$ and enantioselectivity $(57 \%$ ee) were obtained in spite of a high syn-diastereoselectivity $($ syn/anti $=94: 6)$. Moreover, the catalytic system was compatible to the Michael addition of an aldehyde, such as pentanal, which afforded by reaction with nitrostyrene the corresponding Michael adduct in good yield (80\%) and enantioselectivity ( $75 \%$ ee), as shown in Scheme 6.

In 2016, Suzuki et al. reported the synthesis of proline-derived organocatalysts immobilized over an amphiphilic diblock copolymer consisting of poly( $N$-isopropyl acrylamide) and linear poly(ethylene)glycol fragments [26]. This copolymer 11 formed micelles when heated at $50{ }^{\circ} \mathrm{C}$. As shown in Scheme 7, when this catalyst was applied at this temperature to the Michael addition of cyclohexanone to nitrostyrene in water, it yielded the desired product in moderate yield (49\%) and enantioselectivity ( $45 \%$ ee) albeit combined with a good syn-diastereoselectivity (syn/anti $=91: 9)$.
The same year, Tao and Zhang developed the synthesis of novel chiral pyrrolidine-functionalized polyacrylonitrile fiber catalysts which were further investigated in the enantioselective Michael addition of cyclohexanone to aromatic nitroalkenes in water [27]. Among them, catalyst 12 exhibiting quaternary ammonium moieties was selected as optimal since it allowed a range of Michael products to be achieved in uniformly high yields (83-96\%), syndiastereoselectivities (syn/anti $=92: 8-98: 2)$ and enantioselectivities (83-99\% ee), as shown in Scheme 8.

In order to determine whether the organocatalytic Michael reaction between nitroalkenes and aldehydes catalyzed by diphenylprolinol trimethylsilyl ether in water evolved through enamine or enol mechanism, Hayashi et al. recently investigated this reaction in the presence of $\mathrm{H}_{2}{ }^{18} \mathrm{O}$, by monitoring the ratio of ${ }^{18} \mathrm{O}$ incorporated into the final Michael product [28]. This study demonstrated, however, that a ${ }^{16} \mathrm{O} /{ }^{18} \mathrm{O}$ exchange in the aldehyde starting material, occurring through an enamine intermediate, was faster than the Michael reaction. Consequently, the authors concluded that the use of $\mathrm{H}_{2}{ }^{18} \mathrm{O}$ was not appropriate for distinguishing between the formation of an enol or enamine in the Michael reaction.

\subsection{With 1,2-Diamine Catalysts and Derivatives}

Besides proline-derived organocatalysts, a number of chiral 1,2diamine catalysts often including a primary amine have been successfully applied by different groups to enantioselective nitro- 


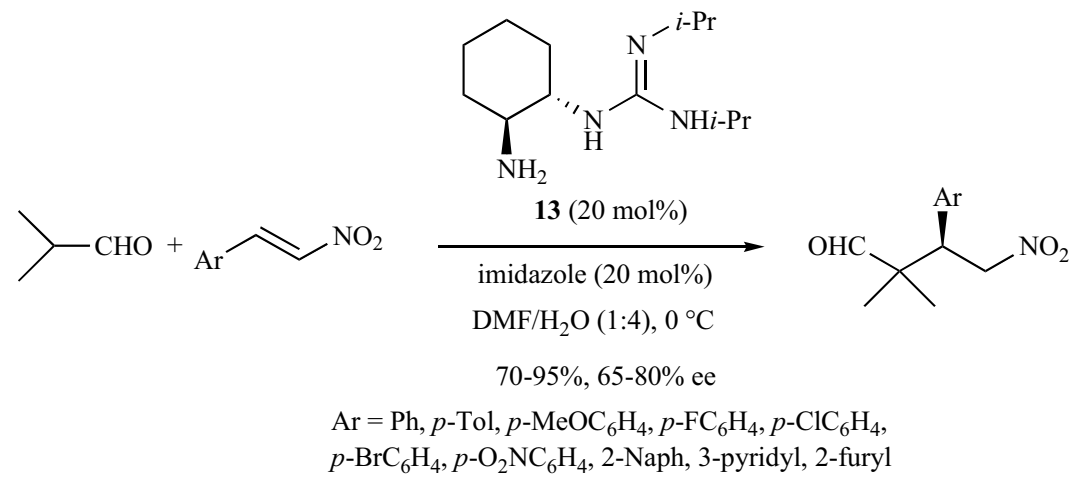

Scheme 9. Michael reaction of isobutyraldehyde and aromatic nitroalkenes with catalyst $\mathbf{1 3}$ in aqueous media.

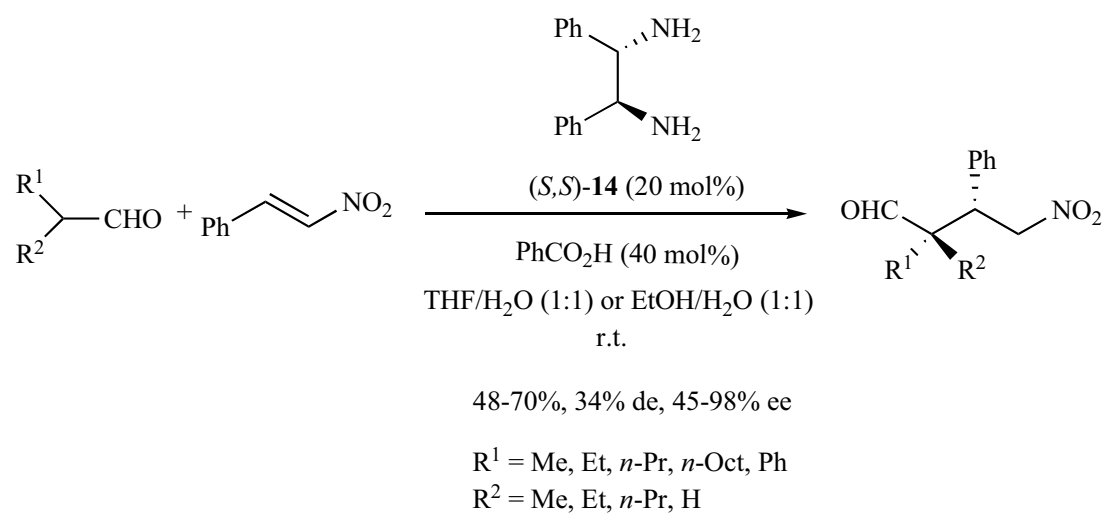

Scheme 10. Michael reaction of aldehydes and nitrostyrene with catalyst $(S, S)-\mathbf{1 4}$ in aqueous media.<smiles>CCOCCOC(=O)C(C)C(=O)NC(=O)N[C@@H](c1ccccc1)C(N)c1ccccc1</smiles><smiles>CC(C)(C=O)/C(=C/C[N+](=O)[O-])c1ccccc1</smiles>

$96 \%, 98 \%$ ee

Scheme 11. Michael reaction of isobutyraldehyde andnitrostyrene with a supramolecular AI-ITQ-HB-supported catalyst in aqueous media.

Michael reactions performed in aqueous media [29]. As a recent example, Najera and Chinchilla have reported the use of chiral primary amine-guanidine catalysts derived from trans-cyclohexane1,2-diamine in enantioselective Michael additions of isobutyraldehyde to aromatic nitroalkenes [30]. When promoting these reactions by catalyst $\mathbf{1 3}$ in the presence of imidazole as rate-accelerating additive in aqueous DMF at $0{ }^{\circ} \mathrm{C}$, they led to a range of chiral $\gamma$ nitroaldehydes in moderate to high yields $(70-95 \%)$ with moderate to good enantioselectivities (65-80\% ee), as shown in Scheme 9.

In 2015, a more simple organocatalyst, such as cheap and commercially available $(S, S)$-diphenylethylenediamine $\mathbf{1 4}$, was investigated by Mlynarski and Rogozinska-Szymczak in aqueous media as promotor in this type of reactions [31]. Indeed, these authors demonstrated that the Michael addition of aldehydes to nitrostyrene could be performed in a 1:1 mixture of THF or EtOH and water when using this catalyst in combination with benzoic acid as additive. As shown in Scheme 10, the reaction of various aldehydes with nitrostyrene led to the corresponding Michael products in moderate yields (48-70\%), low diastereoselectivities $(34 \%$ de) and moderate to high enantioselectivities (45-98\% ee). Noteworthy, uniformly excellent enantioselectivities of $96-98 \%$ ee were obtained for the more demanding conjugate addition of $\alpha, \alpha$ disubstituted aldehydes to nitrostyrene while lower enantioselectivities $(45-50 \%$ ee) were observed with linear aldehydes as substrates.

In 2016, Garcia-Garcia et al. reported the synthesis of a novel mesoscopic and lamellar metal-organic material AI-ITQ-HB from equimolecular quantities of $\mathrm{AlCl}_{3}\left(6 \mathrm{H}_{2} \mathrm{O}\right)$ and 4-heptylbenzoic acid to be used as a host supramolecular catalyst for enantioselective Michael reactions in aqueous media [32]. As shown in Scheme 11, the Michael addition of isobutyraldehyde to nitrostyrene performed at room temperature in the presence of chiral 1,2-diamine $\mathbf{1 5} \mathrm{im}$ mobilized on AI-ITQ-HB in a 1:3 mixture of toluene and water led to the corresponding product in both remarkable yield (96\%) and enantioselectivity ( $98 \%$ ee). Furthermore, the solid could be recycled and reused at least two times.

In 2017, Zlotin and Tukhvatshin developed novel chiral tertiary amine-derived ionic liquid-supported squaramide $\mathbf{1 6}$ to be applied in water as efficient catalyst for enantioselective Michael additions 


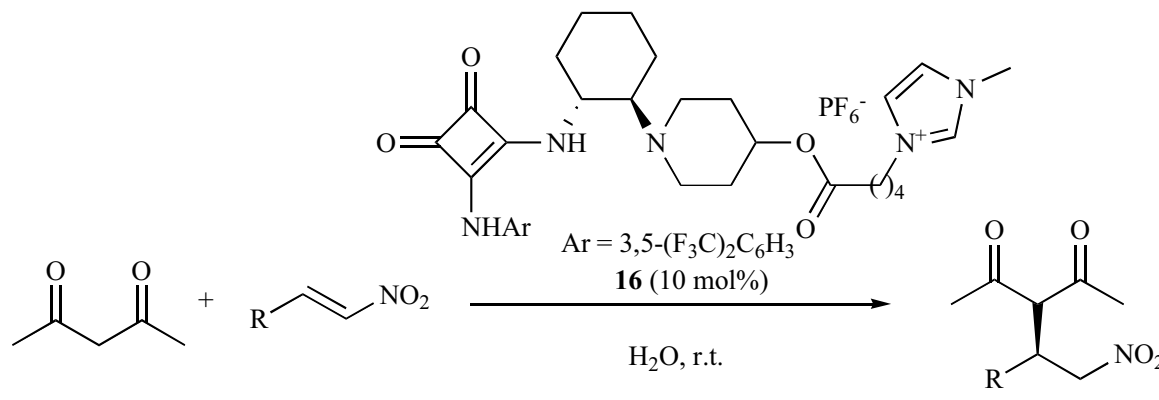

$86-99 \%, 73-99 \%$ ee

$\mathrm{R}=\mathrm{Ph}, p-\mathrm{MeOC}_{6} \mathrm{H}_{4}, p-\mathrm{Tol}, p-\mathrm{ClC}_{6} \mathrm{H}_{4}, 2,4-\mathrm{Cl}_{2} \mathrm{C}_{6} \mathrm{H}_{3}, p-\mathrm{BnOC}_{6} \mathrm{H}_{4}, p-\mathrm{O}_{2} \mathrm{NC}_{6} \mathrm{H}_{4}$, $m$ - $\mathrm{MeOC}_{6} \mathrm{H}_{4}, 3,4-\left[\mathrm{O}\left(\mathrm{CH}_{2}\right)_{2} \mathrm{O}\right] \mathrm{C}_{6} \mathrm{H}_{3}$, 2-thienyl, $i$-Bu, $n$-Hex, $n$-Hept, $(E)$ - $\mathrm{MeCH}=\mathrm{CH}$, (E) $-\mathrm{PhCH}=\mathrm{CH}$, ferrocenyl, cymantrenyl

Scheme 12. Michael reaction of acetylacetone and nitroalkenes with ionic liquid-supported catalyst $\mathbf{1 6}$ in water.<smiles>[R]C=C[N+](=O)[O-]</smiles>

Scheme 13. Michael reaction of malonates and nitroalkenes with catalyst $\mathbf{1 7}$ in brine.

of acetylacetone to nitroalkenes [33]. As shown in Scheme 12, the reactions catalyzed at room temperature in water with $10 \mathrm{~mol} \%$ of this supported organocatalyst afforded the corresponding Michael products in very high yields (86-99\%) with high to excellent enantioselectivities $(73-99 \%$ ee). Notably, the catalyst was readily recoverable and reusable at least 30 times without a significant decrease in both enantioselectivity and activity.

\subsection{With Cinchona Alkaloid Catalysts}

Early in 2007, a cinchona alkaloid-derived organocatalyst, sodium demethylquinine, was applied by Wang et al. at only $1 \mathrm{~mol} \%$ of catalyst loading to promote the addition of malonates to nitrostyrenes in water, providing enantioselectivities of up to $90 \%$ ee [34]. This type of catalysts could also be applied to the construction of quaternary stereocenters through asymmetric Michael addition of trisubstituted carbanions to nitroalkenes performed in water [35]. Ever since, other cinchona alkaloid catalysts have been successfully investigated in enantioselective nitro-Michael reactions. As a recent example, Song and Bae developed the enantioselective Michael addition of malonates to various nitroalkenes based on the use of only $2 \mathrm{~mol} \%$ of dihydroquinine-derived squaramide 17 in brine at room temperature [36]. As shown in Scheme 13, it afforded the corresponding chiral Michael products in both excellent yields (86$99 \%$ ) and enantioselectivities (90-93\% ee). Notably, even unreactive $\alpha$-substituted malonates $(\mathrm{X}=\mathrm{Me}, \mathrm{Cl})$ also gave high yields (90-94\%) combined with excellent enantioselectivities (91-93\% ee).

Later, the same group investigated this catalyst in enantioselective Michael reactions of diethyl dithiomalonate with unreactive $\beta, \beta$-disubstituted nitroalkenes performed in brine [37]. In this case, a higher catalyst loading $(15 \mathrm{~mol} \%)$ and the presence of a hydrophobic cosolvent as an additive, such as ortho-xylene, were required to achieve good results, as shown in Scheme 14. These conditions allowed a wide variety of chiral Michael products to be achieved in generally excellent enantioselectivities of up to $96 \%$ ee and yields of up to $99 \%$ ee when using diverse aryl and heteroaryl substituted nitroalkenes. Especially, substituents in meta- or parapositions were all excellent substrates in the reaction regardless of the electronic nature of the aromatic substituent. Although the reaction of a sterically demanding ortho-substituted $\left(\mathrm{R}^{2}=o-\mathrm{MeOC}_{6} \mathrm{H}_{4}\right)$ nitroalkene also provided an excellent enantioselectivity (92\% ee), a significant lower yield (22\%) was observed in this case probably due to steric hindrance. Excellent enantioselectivities (92-95\% ee) were also achieved in the reaction of heteroaromatic substrates $\left(\mathrm{R}^{2}\right.$ $=2$-furyl, 2-thienyl, 3-thienyl). In addition, aliphatic substrates $\left(\mathrm{R}^{2}\right.$ $=\mathrm{Bn}, \mathrm{CH}_{2} \mathrm{Bn}, i$-Pr) were also compatible to the catalytic system, 

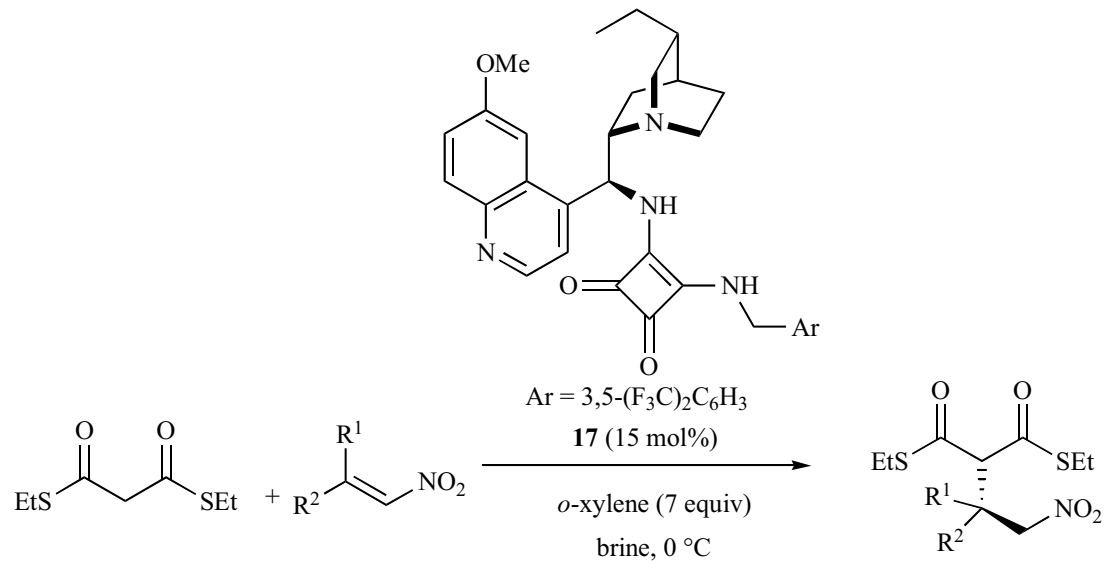

$$
\begin{aligned}
& \mathrm{R}^{1}=\mathrm{Me}, \mathrm{Et} \\
& \mathrm{R}^{2}=\mathrm{Ph}, p-\mathrm{Tol}, p-\mathrm{MeOC}_{6} \mathrm{H}_{4}, o-\mathrm{MeOC}_{6} \mathrm{H}_{4}, p-\mathrm{ClC}_{6} \mathrm{H}_{4}, p-\mathrm{BrC}_{6} \mathrm{H}_{4}, \\
& m \text { - } \mathrm{MeOC}_{6} \mathrm{H}_{4}, 3,4,5-\mathrm{F}_{3} \mathrm{C}_{6} \mathrm{H}_{2}, m-\mathrm{Tol}_{4}, m-\mathrm{F}_{3} \mathrm{CC}_{6} \mathrm{H}_{4}, p-\mathrm{F}_{3} \mathrm{CC}_{6} \mathrm{H}_{4}, m-\mathrm{ClC}_{6} \mathrm{H}_{4}, \\
& \text { 2-thienyl, 3-thienyl, 2-furyl, } i-\mathrm{Bu}, \mathrm{BnCH}_{2}, \mathrm{Bn}
\end{aligned}
$$

Scheme 14. Michael reaction of diethyl dithiomalonate and unreactive $\beta, \beta$-disubstitutednitro alkenes with catalyst 17 in brine.

$$
\text { addition of acetylacetone: }
$$

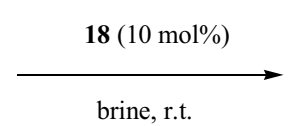

$\mathrm{R}=\mathrm{Ph}, p-\mathrm{FC}_{6} \mathrm{H}_{4}, p-\mathrm{ClC}_{6} \mathrm{H}_{4}, p-\mathrm{BrC}_{6} \mathrm{H}_{4}, p-\mathrm{Tol}, p-\mathrm{MeOC}_{6} \mathrm{H}_{4}$,

addition of $\beta$-ketoesters:

$$
o \text { - } \mathrm{ClC}_{6} \mathrm{H}_{4}, 2,4-\mathrm{Cl}_{2} \mathrm{C}_{6} \mathrm{H}_{3}, 2 \text {-thienyl, Et, } i \text {-Pr, } t \text {-Bu }
$$

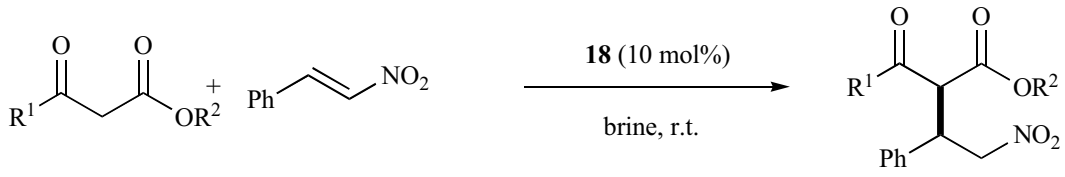

90- $>99 \%$ conversion, $10-28 \%$ de, $94-99 \%$ ee

$$
\begin{aligned}
& \mathrm{R}^{1}=\mathrm{Me}, \mathrm{OMe} \\
& \mathrm{R}^{2}=\mathrm{Me}, \mathrm{Et}, i-\mathrm{Pr}, t-\mathrm{Bu}
\end{aligned}
$$

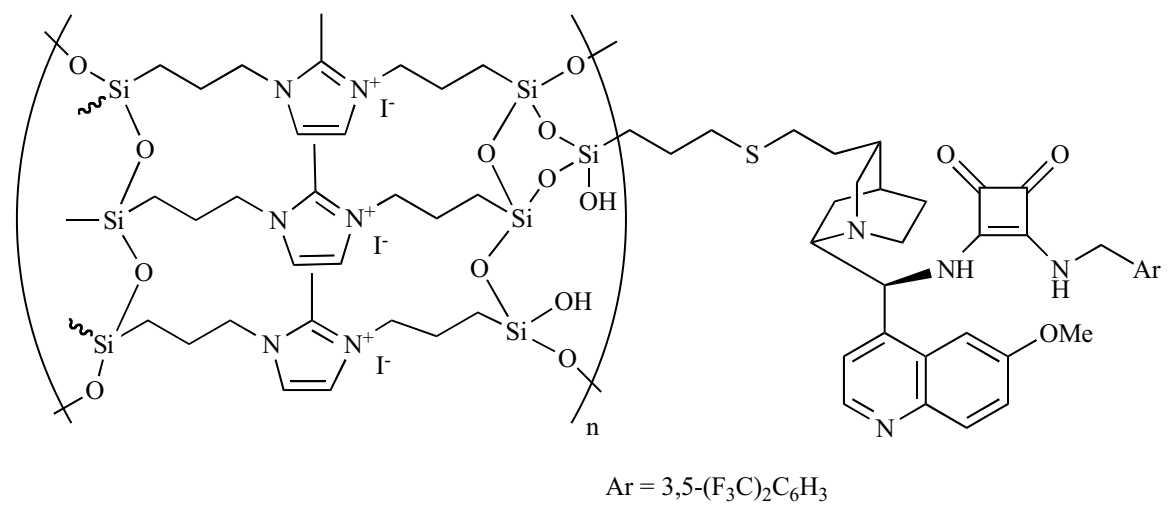

18

Scheme 15. Michael reaction of 1,3-dicarbonyl compounds and nitroalkenes with organic-inorganic hybrid silica-supported catalyst $\mathbf{1 8}$ in brine.

leading to the corresponding products in moderate to good yields (70-90\%) albeit combined with lower enantioselectivities (32-61\% ee). The synthetic utility of this novel methodology was demonstrated in the conversion of some products into pharmaceutically interesting chiral GABA analogs bearing an all-carbon quaternary stereogenic center.
In 2014, Liu et al. incorporated a chiral cinchona alkaloidderived squaramide organocatalyst onto imidazolium-based organic-inorganic hybrid silica to construct novel bifunctional heterogeneous catalyst 18 [38]. The latter was further investigated as catalyst in enantioselective Michael additions of 1,3-dicarbonyl compounds to nitroalkenes in brine, as shown in Scheme 15. The reaction of acetylacetone with a range of aromatic as well as aliphatic 

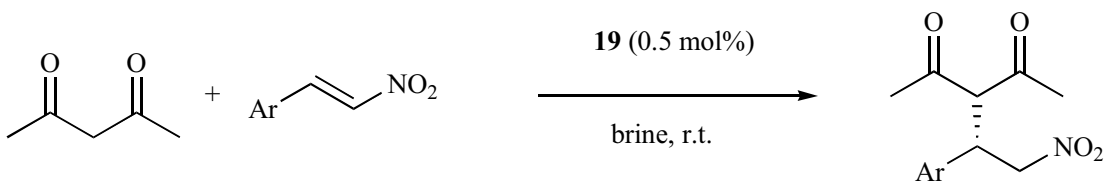

$93-97 \%, 96-99 \%$ ee

$\mathrm{Ar}=\mathrm{Ph}, p-\mathrm{FC}_{6} \mathrm{H}_{4}, p-\mathrm{ClC}_{6} \mathrm{H}_{4}, m-\mathrm{ClC}_{6} \mathrm{H}_{4}, p-\mathrm{Tol}, o-\mathrm{ClC}_{6} \mathrm{H}_{4}$, $p-\mathrm{BrC}_{6} \mathrm{H}_{4}, p-\mathrm{F}_{3} \mathrm{CC}_{6} \mathrm{H}_{4}, p-\mathrm{MeOC}_{6} \mathrm{H}_{4}, m-\mathrm{MeOC}_{6} \mathrm{H}_{4}, p-\mathrm{MeOC}_{6} \mathrm{H}_{4}$

preparation of catalyst 19:

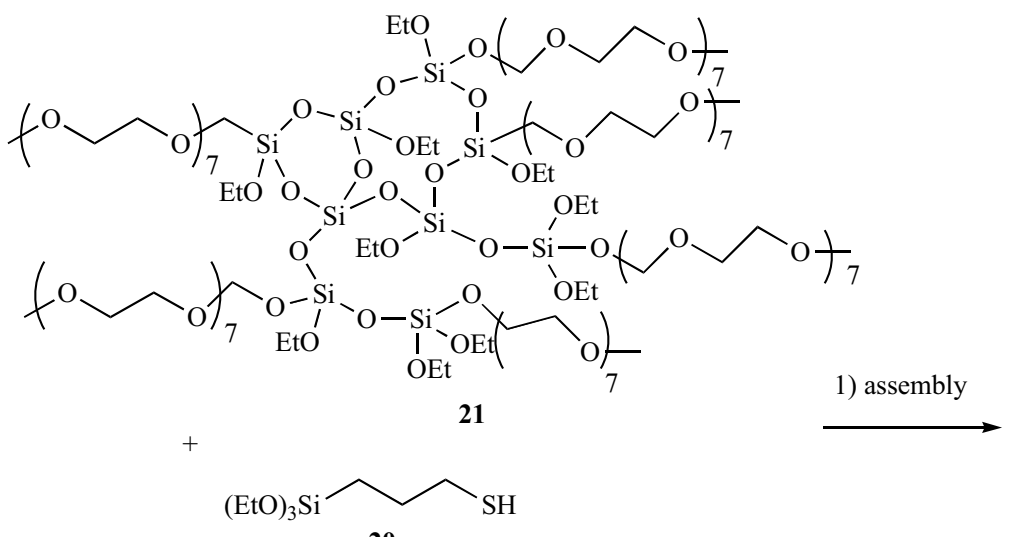

20

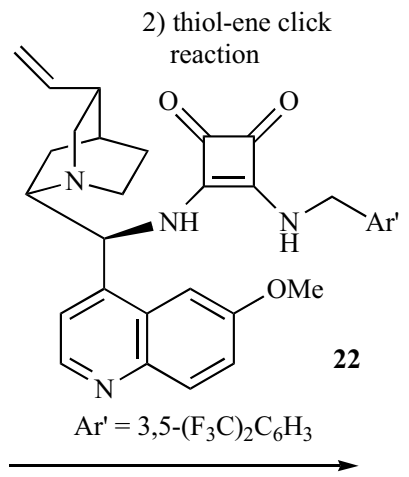

19

Scheme 16. Michael reaction of acetylacetone and aromaticnitroalkenes with polyethoxysiloxane-supported catalyst 19 in brine.

nitroalkenes in the presence of $10 \mathrm{~mol} \%$ of this catalyst at room temperature in brine yielded the corresponding Michael products in both uniformly remarkable conversions (93->99\%) and enantioselectivities $(97-99 \%$ ee). In the case of aromatic nitroalkenes, the nature and electronic properties of the substituents on the aromatic moiety $(\mathrm{R}=$ aryl) did not affect the enantioselectivity of the reaction. The same reaction conditions were applied to other 1,3dicarbonyl compounds, such as $\beta$-ketoesters, which reacted with nitrostyrene to give the corresponding Michael adducts in high to complete conversion (90->99\%) and uniformly excellent enantioselectivities (94-99\% ee) although combined with low diastereoselectivities (10-28\% de), as shown in Scheme 15. Notably, this novel heterogeneous catalyst was readily recovered via simple filtration, and could be resused through multiple cycles (up to eight) without loosing enantioselectivity and catalytic activity.

Later in 2016, the same authors reported the synthesis of another heterogeneous catalyst based on the same cinchona alkaloidderived squaramide [39]. Its synthesis was based on the self- templating assembly of (triethoxysilyl)propanethiol 20 with amphiphilic poly(ethyleneglycol) monomethyl ether-modified hyperbranched polyethoxysiloxane $\mathbf{2 1}$, leading to the corresponding mercapto-functionalized mesostructured nanoparticles, which further reacted with chiral squaramide $\mathbf{2 2}$ through a thiol-ene click reaction to afford catalyst 19 (Scheme 16). When applied at only $0.5 \mathrm{~mol} \%$ of catalyst loading to promote the enantioselective Michael addition of acetylacetone toaromatic nitroalkenes in brine, this catalyst allowed the corresponding chiral products to be obtained in both uniformly excellent yields (93-97\%) and enantioselectivities (96$99 \%$ ee) irrespective to the nature of the substituents beared by the aromatic moiety of the nitroalkenes, as shown in Scheme $\mathbf{1 6}$. Moreover, it was found that this novel catalyst could be recovered and reused several times without effect on its catalytic efficiency.

\subsection{With Peptide Catalysts}

Early in 2006, peptides [40] were employed by Cordova et al. as organocatalysts in enantioselective Michael additions of ketones 


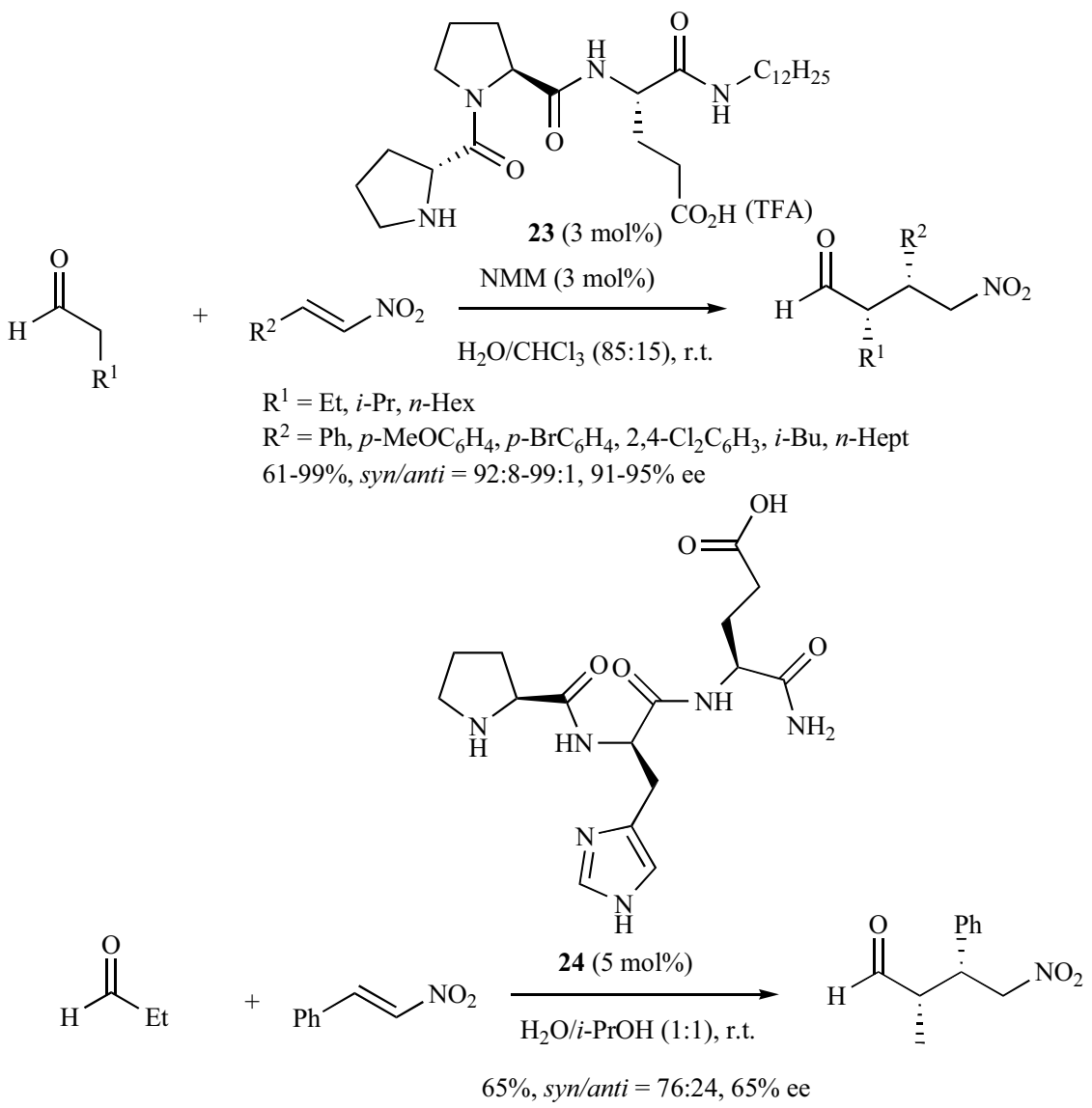

Scheme 17. Michael reactions of aldehydes and nitroalkenes with catalysts 23-24 in aqueous media.

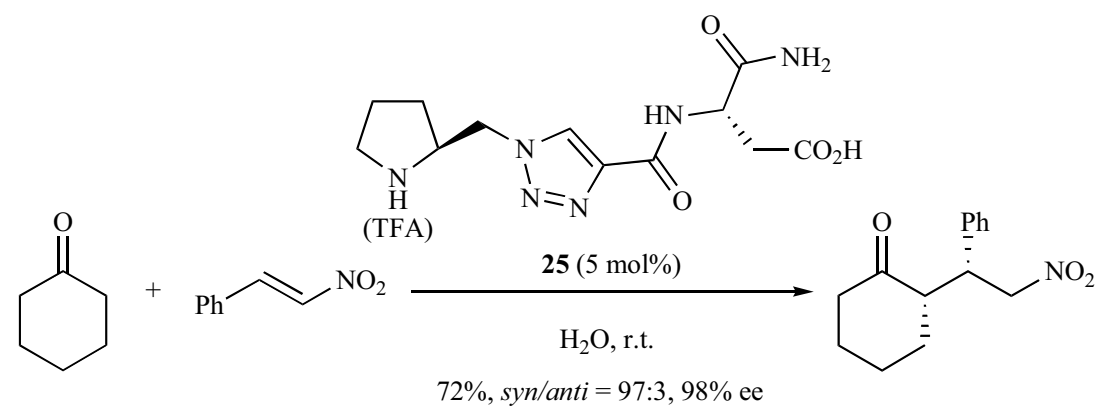

Scheme 18. Michael reaction of cyclohexanone and nitrostyrene with catalyst $\mathbf{2 5}$ in water.

to nitrostyrenes in mixed solvents, such as $N$-methylpyrrolidone or DMSO and water, providing enantioselectivities of $29-99 \%$ ee [41]. In 2014, Wennemers et al. reported the use of amphiphilic tripeptide $\mathbf{2 3}$ to catalyze the asymmetric conjugate addition of aldehydes to nitroalkenes in aqueous media [42]. The best results were obtained by using $3 \mathrm{~mol} \%$ of catalyst 23 in water containing $15 \%$ (v/v) of chloroform as an additive along with $3 \mathrm{~mol} \%$ of $\mathrm{N}$ methylmorpholine (NMM) at room temperature. As shown in Scheme 17, under these conditions, the corresponding Michael products were produced in good to quantitative yields (61-99\%), high $s y n$-diastereoselectivities (syn/anti $=92: 8-99: 1)$ and enantioselectivities (91-95\% ee). Notably, aliphatic nitroolefins provided comparable results than aromatic ones $(61-99 \%$ yields vs $81-99 \%$ yields, syn/anti $=97: 3-99: 1$ vs $92: 8-99: 1,89-94 \%$ ee vs $92-95 \%$ ee). It must be noted that even in pure water, the reactions still gave excellent results with slightly lower enantioselectivities (84-94\% ee). Earlier in 2013, the Michael addition of propionaldehyde to nitrostyrene was investigated by Rahman et al. in the presence of another tripeptide catalyst, such as $\mathbf{2 4}$, leading to the corresponding product in moderate yield (65\%), syn-diastereoselectivity (syn/anti $=76: 24)$ and enantioselectivity $(65 \%$ ee) in aqueous isopropanol (Scheme 17) [43].

In 2014, Chandrasekhar and Mainkar reported the synthesis of novel peptidomimetic triazole-based organocatalyst $\mathbf{2 5}$ derived from proline to be applied to promote aqueous Michael additions of ketones to nitrostyrene [44]. An excellent result was achieved in the reaction of cyclohexanone with this nitroalkene performed in pure water at room temperature since the corresponding product was obtained in excellent $s y n$-diastereoselectivity $(s y n / a n t i=97: 3)$ and enantioselectivity (98\% ee) combined with a good yield (72\%), as illustrated in Scheme 18. It must be noted that the results depicted in Schemes 17-18 could also appear in previous Section 2.1 dealing with proline-derived catalysts. 


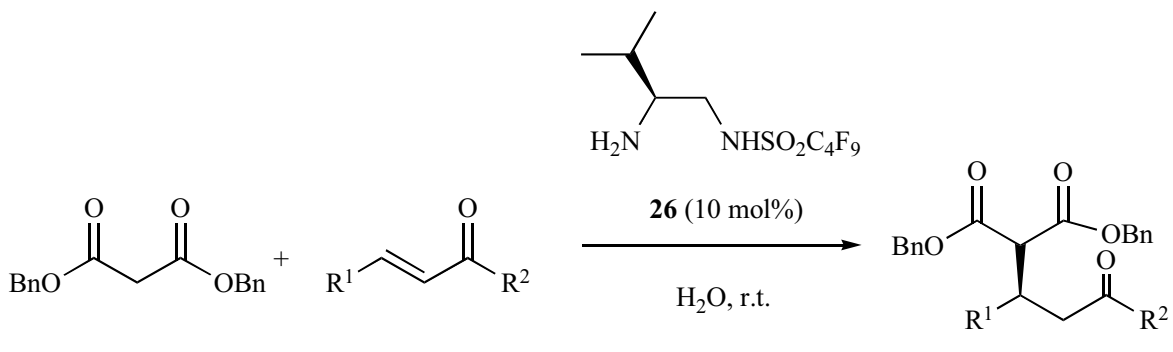

$8-86 \%, 90->99 \%$ ee

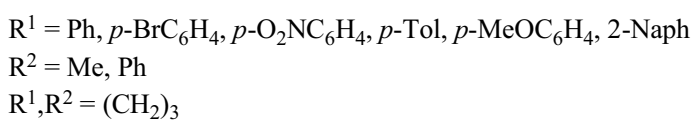

Scheme 19. Michael reaction of dibenzyl malonate and $\alpha, \beta$-unsaturated ketones with catalyst 26 in water.<smiles>[R]C=CC(C)=O</smiles>

$\mathrm{R}=\mathrm{Ph}, o-\mathrm{ClC}_{6} \mathrm{H}_{4}, m-\mathrm{ClC}_{6} \mathrm{H}_{4}, p-\mathrm{ClC}_{6} \mathrm{H}_{4}, o-\mathrm{MeOC}_{6} \mathrm{H}_{4}, p-\mathrm{MeOC}_{6} \mathrm{H}_{4}$, $m-\mathrm{O}_{2} \mathrm{NC}_{6} \mathrm{H}_{4}, p-\mathrm{O}_{2} \mathrm{NC}_{6} \mathrm{H}_{4}, o-\mathrm{Tol}, 2-\mathrm{Naph}, n-\mathrm{Bu}, i-\mathrm{Pr}$

Scheme 20. Michael reaction of 4-hydroxycoumarin and $\alpha, \beta$-unsaturated ketones with catalyst $(S, S)$-14 in water in the presence of benzoic acid as additive.

\section{ENANTIOSELECTIVE ORGANOCATALYTIC MICHAEL REACTIONS OF $\alpha, \beta$-UNSATURATED CARBONYL COM- POUNDS}

\subsection{With 1,2-Diamine and 1,2-Aminoalcohol Catalysts and Derivatives}

In addition to the use of nitroolefins as electrophilic partners in enantioselective aqueous organocatalytic Michael additions, various types of $\alpha, \beta$-unsaturated carbonyl compounds have also been successfully employed in these reactions using different types of organocatalysts. Among them, a range of chiral 1,2-diamine derivatives have encountered success. As a recent example, Miura et al. reported the use of chiral $\beta$-aminosulfonamide organocatalysts in water and without additives to promote the enantioselective Michael addition of dibenzyl malonate to $\alpha, \beta$-unsaturated ketones [45]. The reaction was catalyzed with $10 \mathrm{~mol} \%$ of perfluorobutanesulfonamide $\mathbf{2 6}$ in water at room temperature, as shown in Scheme 19. When aromatic $\alpha, \beta$-unsaturated ketones were used as substrates, the corresponding conjugate products were obtained in uniformly high enantioselectivities ( $90->99 \%$ ee) and good yields (74$86 \%)$ except for chalcone $\left(\mathrm{R}^{1}=\mathrm{R}^{2}=\mathrm{Ph}\right)$ which provided the corresponding enantiopure product in low yield $(8 \%)$. The involvement of cyclohexanone as electrophilic partner resulted in low yield $(23 \%)$ and moderate enantioselectivity ( $42 \%$ ee).

With the aim of developing a novel and environmentally friendly route to anticoagulant warfarin and its analogues, Mlynarski and Rogozinska-Szymczak investigated the Michael reaction of 4-hydroxycoumarin with $\alpha, \beta$-unsaturated ketones in water in the presence of primary amine catalysts [46]. Among them, $(S, S)$ diphenylethylenediamine $\mathbf{1 4}$ was found the most effective catalyst when used in the presence of $20 \mathrm{~mol} \%$ of benzoic acid as an additive in water. Moreover, the process was accelerated by ultrasound, leading to the corresponding chiral warfarin derivatives in good to quantitative yields (73-98\%) and moderate to good enantioselectivities $(60-76 \%$ ee), as shown in Scheme 20. In particular, warfarin itself $(\mathrm{R}=\mathrm{Ph})$ was obtained in $98 \%$ yield with $72 \%$ ee. While comparable enantioselectivities were achieved for both aromatic and aliphatic $\alpha, \beta$-unsaturated ketones, the latter provided slightly lower yields than the former (73-81\% vs $90-98 \%$ ).

So far, only few organocatalytic enantioselective additions of C-nucleophiles to hindered $\beta, \beta$ '-disubstituted Michael acceptors have been successfully developed [36]. In this context, Singh et al. have investigated the enantioselective vinylogous Michael reaction of 2-siloxyfurans with cyclic $\alpha, \beta$-unsaturated ketones in the presence of $(R, R)$-diphenylethylenediamine 14 (scheme 21) as organocatalyst [47]. An acid additive, such as trichloroacetic acid, was needed to achieve good results. Among solvents, dichloromethane was selected as most efficient in the presence of water. The reaction of cyclohexenone $\left(\mathrm{R}^{1}=\mathrm{H}, \mathrm{n}=1\right)$ with unsubstituted 2-siloxyfuran led to the corresponding chiral cyclohexanone in high yield (92\%) and excellent diastereo- and enantioselectivities of $90 \%$ de and $97 \%$ ee, respectively. Noteworthy, the reaction of more challenging $\beta$ substituted cyclohexenones bearing methyl, 3-oxo-methyl ester, styryl, and para-fluorostyryl substituents, all afforded the corresponding cyclohexanone-connected $\gamma$-butenolides exhibiting a quaternary stereogenic center in excellent syn-diastereo- and enantioselectivities (92-98\% de, 96->99\% ee, respectively) combined with good yields $(51-82 \%)$. The scope of the process was extended to cyclic $\alpha, \beta$-unsaturated ketones other than cyclohexenones, such as $\beta$-substituted cyclopentenone as well as eight-, twelve-, and fif- 


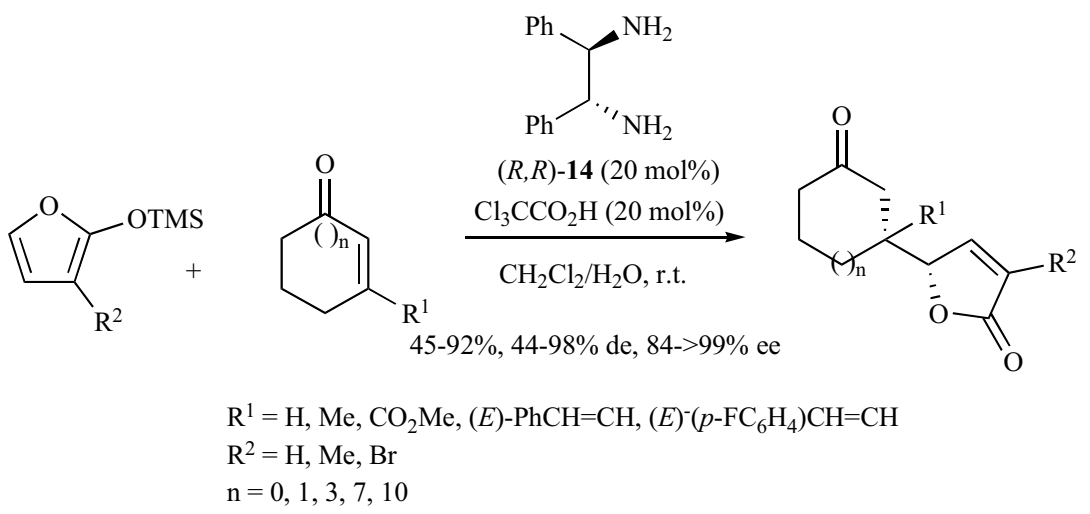

Scheme 21. Vinylogous Michael reaction of 2-siloxyfurans and cyclic $\alpha, \beta$-unsaturated ketones with catalyst $(R, R)$-14 in aqueous media.

$$
\mathrm{MeNO}_{2}
$$

Scheme 22. Michael reaction of nitromethane and $\alpha, \beta$-unsaturated aldehydes with catalyst 27 in aqueous media.

teen-membered cyclic $\alpha, \beta$-unsaturated ketones which all provided the corresponding Michael products in uniformly high enantioselectivities (88-96\% ee) and good yields (51-62\%). The diastereoselectivity was lower $(56-60 \%$ de) for eight-membered and fifteenmembered cyclic enones, while the twelve-membered enones provided an excellent diastereomeric ratio $(94 \%$ de). Furthermore, 3substituted-2-siloxyfurans $\left(\mathrm{R}^{2} \neq \mathrm{H}\right)$ were also compatible substrates with high enantioselectivities $(84-98 \%$ ee) albeit with lower diastereoselectivities (30-44\% de) and moderate yields (45-55\%).

In 2015, Zhang and Tu reported the synthesis of novel watercompatible spiropyrrolidine organocatalysts bearing a triazole unit which were further investigated as promoters in the enantioselective Michael addition of nitromethane to $\alpha, \beta$-unsaturated aldehydes [48]. Among them, 1-adamantyl-substituted catalyst 27 was found optimal when employed in the presence of benzoic acid as an additive in a 1:1 mixture of trifluoroethanol and water as solvent. As shown in Scheme 22, the reaction of nitromethane with a variety of $\alpha, \beta$-unsaturated aldehydes led to the corresponding Michael products in good to high yields (63-88\%) and high enantioselectivities $(83-95 \%$ ee). The lowest enantioselectivities $(83-88 \%$ ee) were generally observed in the reaction of aliphatic. $\alpha, \beta$-unsaturated aldehydes. It must be noted that the results depicted in Scheme 22 could also appear in Section 3.2 dealing with proline-derived catalysts.

The succinimide unit is present in a number of natural and biologically relevant products. In this context, Najera et al. have de- veloped enantioselective organocatalytic Michael additions of aldehydes to maleimides performed in aqueous media, leading to this type of chiral products. Among a variety of chiral cyclohexane-1,2diamine-derived organocatalysts, chiral primary amine-guanidine 13 was selected in a first study to allow these reactions to be achieved in high yields (85-99\%) with good to excellent enantioselectivities $(74-95 \%$ ee) when using imidazole as additive and 2:1 mixture of DMF and water as solvent, as shown in Scheme 23 [49]. Especially, the reaction of $\alpha, \alpha$-disubstituted aldehydes provided the highest enantioselectivities (84-95\% ee) in comparison to monosubstituted ones $(74-87 \%$ ee). In a second study, the same authors showed that using simple $(S, S)$-diphenylethylenediamine $\mathbf{1 4}$ as organocatalyst in the same reactions in the presence of hexanedioic acid as additive in the same aqueous solvent led to the desired chiral functionalized succinimides in high to quantitative yields (90-99\%) with moderate to excellent enantioselectivities (59-91\% ee), as shown in Scheme 23 [50]. More recently, these authors promoted these reactions with $10 \mathrm{~mol} \%$ of primary amineaminopyrimidine organocatalyst $\mathbf{2 8}$ in the presence of the same additive and solvent, which allowed chiral succinimides to be obtained in good to high yields (70-92\%) and enantioselectivities (7693\% ee), as shown in Scheme 23 [51].

In 2016, another chiral 1,2-diamine organocatalyst 15 was used by Garcia-Garcia et al. in the presence of a host supramolecular catalyst, such as mesoscopic and lamellar metal-organic material AI-ITQ-HB, in enantioselective Michael additions of dimethyl- 


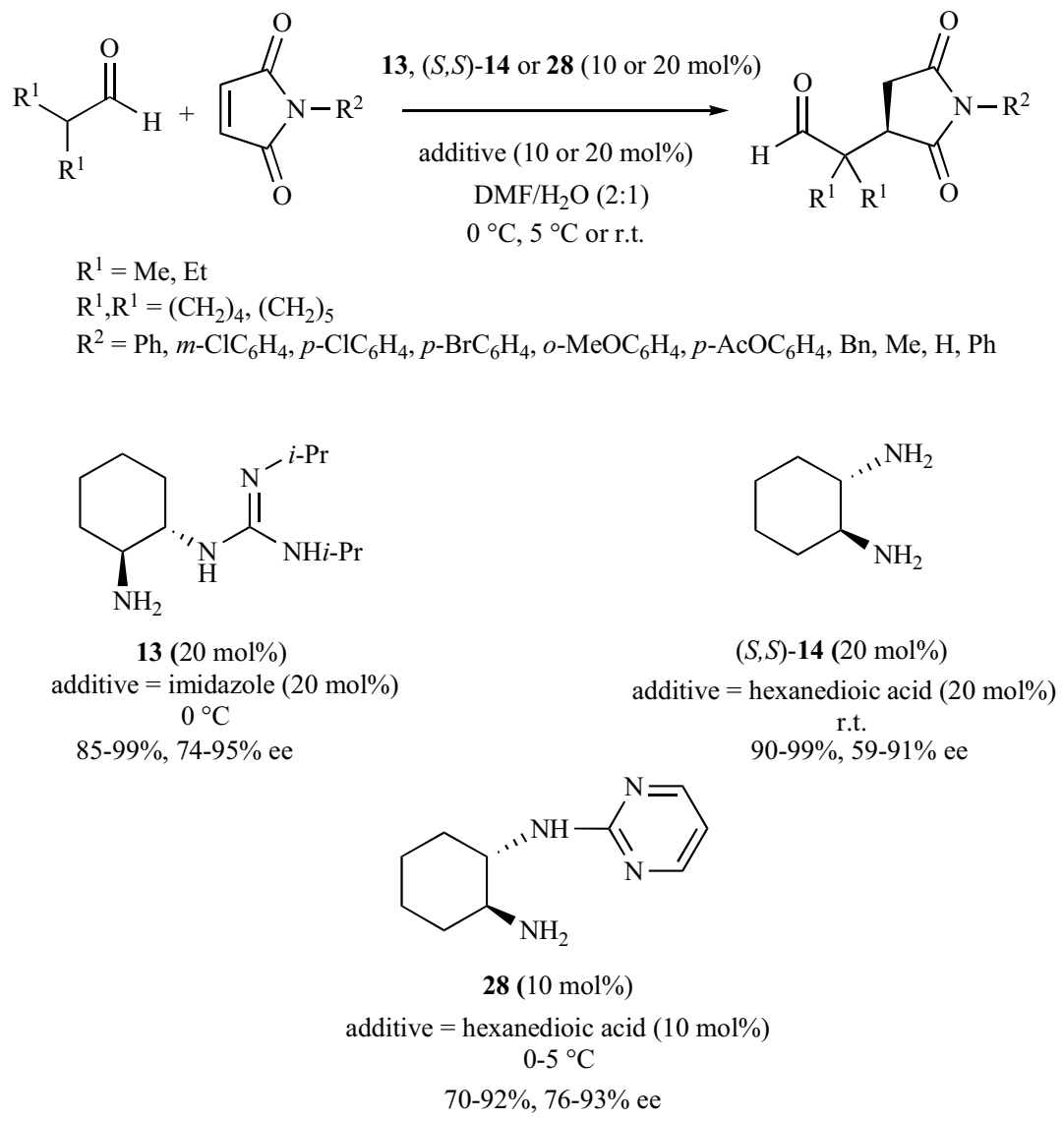

Scheme 23. Michael reaction of aldehydes and maleimides with catalysts 13, $(S, S)-\mathbf{1 4}$ and 28 in aqueous media.

$$
\begin{aligned}
& \text { 供 } \\
& \mathrm{Ar}=3,5-\left(\mathrm{F}_{3} \mathrm{C}\right)_{2} \mathrm{C}_{6} \mathrm{H}_{3} \\
& \mathrm{MeO}_{\mathrm{OMe}^{+}}^{\mathrm{O}} \\
& \longrightarrow \\
& 15 \text { (10 mol\%) } \\
& \text { AI-ITQ-HB (30 mol\%) } \\
& \text { toluene } / \mathrm{H}_{2} \mathrm{O}(1: 2) \text {, r.t. }
\end{aligned}
$$
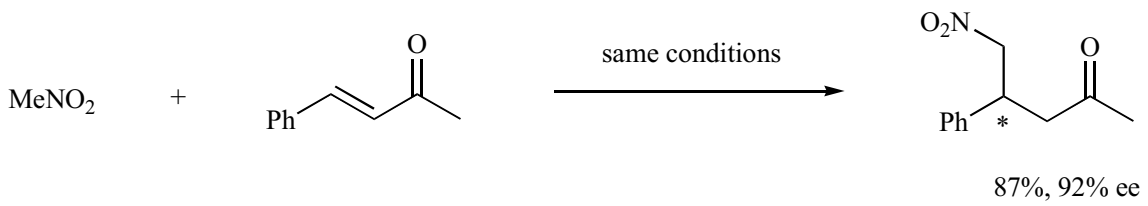

Scheme 24. Michael reactions of nitromethane and dimethylmalonate with benzalacetone with a supramolecular AI-ITQ-HB-supported catalyst in aqueous media.

malonate and nitromethane to $\alpha, \beta$-unsaturated ketones [32]. As shown in Scheme 24, the reaction of dimethylmalonate with benzalacetone performed in a 1:2 mixture of toluene and water at room temperature led to the corresponding Michael product in both remarkable yield $(98 \%)$ and enantioselectivity $(96 \%$ ee). When the same reaction conditions were applied to the addition of nitromethane to benzalacetone, the corresponding product was achieved with slightly lower yield $(87 \%)$ and enantioselectivity (92\% ee), as shown in Scheme 24.
A number of asymmetric domino reactions [52] included an enantioselective organocatalytic Michael addition as first step. As a recent example, Shi and Yang reported asymmetric domino Michael/aldol reactions catalyzed by recyclable polyethyleneglycol(PEG)-supported chiral 1,2-aminoalcohol and 1,2-diamine catalysts in water [53]. The reaction occurred between ethyl benzoylacetate and aromatic $\alpha, \beta$-unsaturated ketones in the presence of glyoxylic acid as additive at room temperature in water to give the corresponding highly functionalized chiral cyclohexanones as al- 


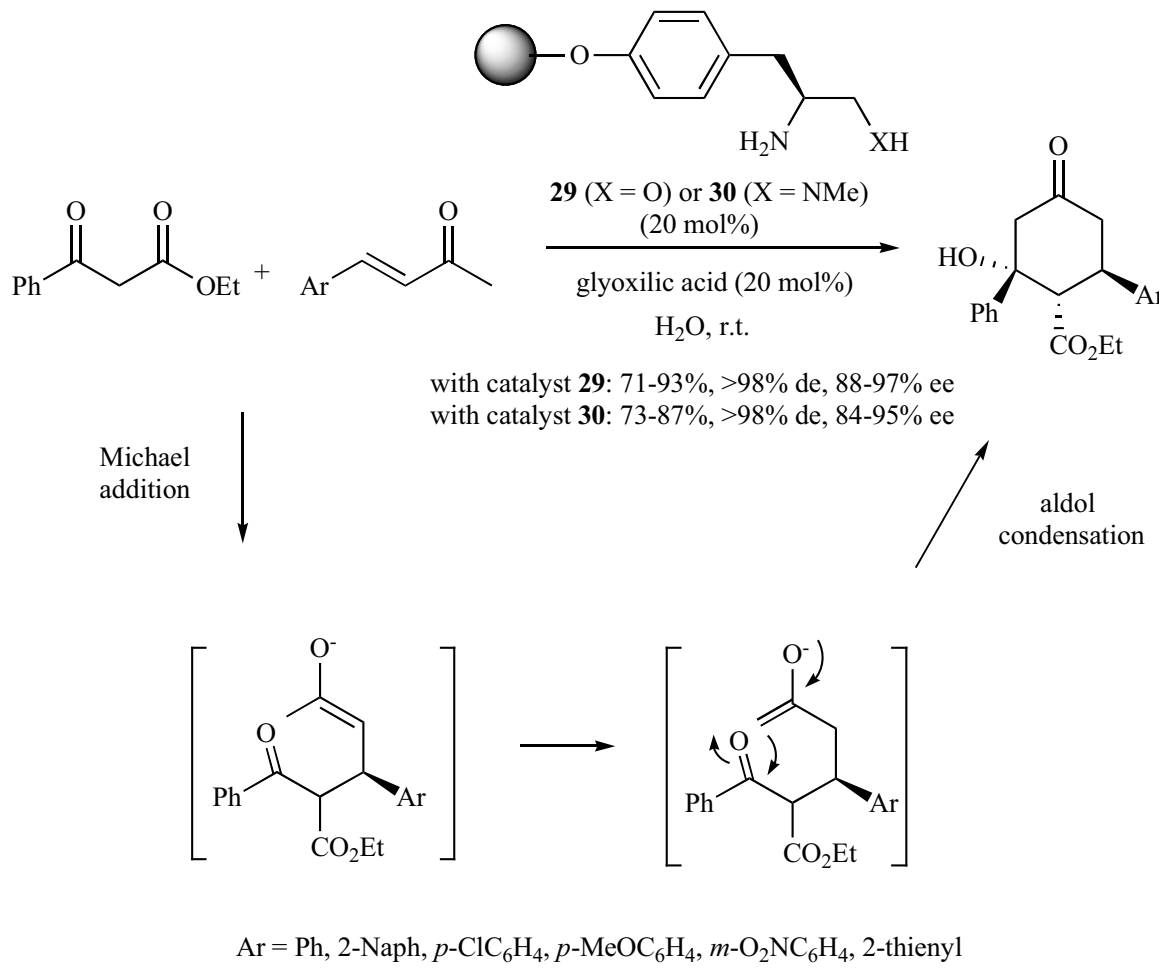

Scheme 25. Domino Michael/aldol reaction with PEG-supported 1,2-aminoalcohol and 1,2-diamine catalysts 29-30 in water.

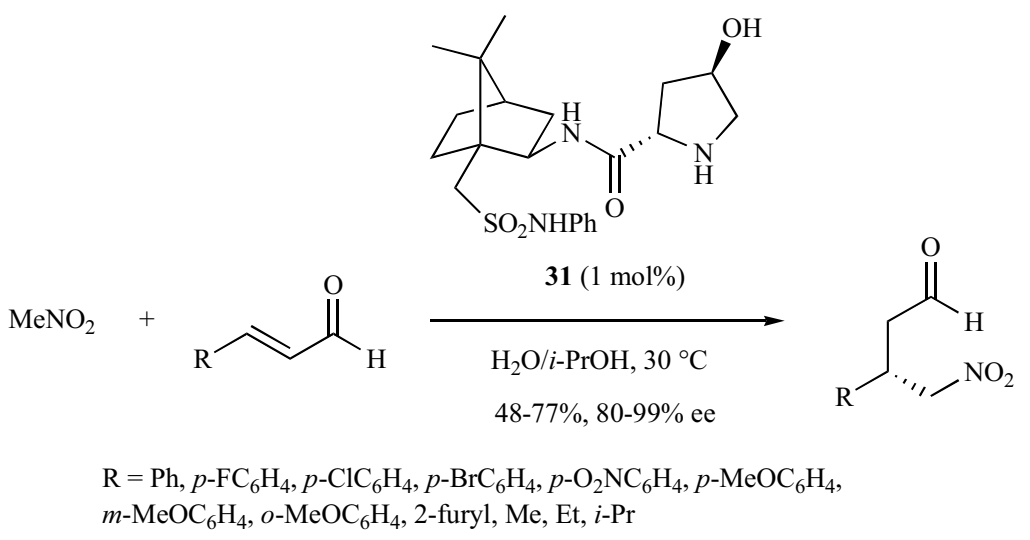

Scheme 26. Michael reaction of nitromethane and $\alpha, \beta$-unsaturated aldehydes with catalyst 31 in aqueous media.

most single diastereomers $(>98 \%$ de) in good to high yields (71$93 \%$ ) and enantioselectivities (84-97\% ee). Comparable yields and stereoselectivities were achieved by using chiral 1,2-aminoalcohol 29 or 1,2-diamine 30, as shown in Scheme 25. Notably, it was demonstrated that even after four reaction cycles, the stereoselectivities remained inaltered while the catalyst activity was slightly decreased ( $83 \%$ to $70 \%$ yield). It must be noted that this study represented a rare example of highly efficient enantioselective domino reaction performed in pure water.

It must be noted that in 2014, Matsubara and Asano described a novel methodology for the asymmetric synthesis of $\beta$ mercaptolactones based on an enantioselective sulfa-Michael addition catalyzed by a chiral cyclohexane-1,2-diamine-derived thiourea catalyst in aqueous acetonitrile at $25{ }^{\circ} \mathrm{C}$, providing only modest enantioselectivities $(21 \%$ ee) in the presence of water [54] while enantioselectivities of up to $90 \%$ ee were achieved in dichloromethane as solvent.

\subsection{With Proline-Derived Catalysts}

Various proline-derived organocatalysts have been employed to promote highly enantioselective conjugate additions of $\mathrm{C}$ nucleophiles to $\alpha, \beta$-unsaturated carbonyl compounds [15c,g, 1,55$]$. In a recent example, Uang and Huang reported the enantioselective Michael addition of nitromethane to $\alpha, \beta$-unsaturated aldehydes performed in aqueous isopropanol by using pyrrole-derived camphorsulfonamide-based catalyst 31 at only $1 \mathrm{~mol} \%$ of catalyst loading [56]. As shown in Scheme 26, the reaction afforded the corresponding chiral Michael products in moderate to high yields (48$77 \%)$ and high enantioselectivities $(80-99 \%$ ee) without using acid additive. Aromatic as well as aliphatic $\alpha, \beta$-unsaturated aldehydes were tolerated, providing comparable excellent enantioselectivities although the latter substrates, such as crotonaldehyde, 2-pentenal, and 4-methyl-2-pentenal, gave lower yields than the former substrates $(48-56 \%$ vs $48-77 \%)$. 
<smiles>C/C(=C1/C(=O)N(C(=O)c2ccccc2)c2ccncc21)c1ccccc1</smiles><smiles>O=CC=CCCCCCCC(=O)c1ccccc1</smiles><smiles>[Y10]C(CC=O)CC(=C1C(=O)N(C(C)(C)C)c2ccccc21)c1ccccc1</smiles>

$16-85 \%, E / Z=87: 13->95: 5,82-94 \%$ ee

$\mathrm{Ar}=\mathrm{Ph}, p-\mathrm{ClC}_{6} \mathrm{H}_{4}, p-\mathrm{FC}_{6} \mathrm{H}_{4}, p-\mathrm{O}_{2} \mathrm{NC}_{6} \mathrm{H}_{4}, p-\mathrm{BrC}_{6} \mathrm{H}_{4}, p-\mathrm{F}_{3} \mathrm{CC}_{6} \mathrm{H}_{4}, o-\mathrm{BrC}_{6} \mathrm{H}_{4}$ $p$ - $\mathrm{Tol}, p$ - $\mathrm{MeOC}_{6} \mathrm{H}_{4}, o-\mathrm{MeOC}_{6} \mathrm{H}_{4}, 2$-furyl, 1-Naph $\mathrm{R}=\mathrm{H}, 3-\mathrm{Cl}, 4-\mathrm{Cl}, 3-\mathrm{Br}$, 4-Br, 4-Me, 4-OMe, 2-OMe

Scheme 27. Vinylogous Michael reaction of 3-alkylidene oxindoles and aromatic $\alpha, \beta$-unsaturated aldehydes with catalyst 32 in aqueous media.

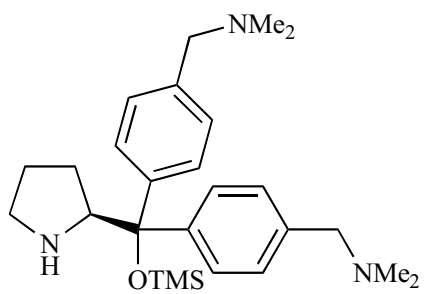

33 (10 mol\%)<smiles></smiles>

$15-76 \%, 34-80 \%$ de, $86-96 \%$ ee

$\mathrm{R}^{1}=n$-Bu, Me, Et, $n$-Pr, $n$-Pent, Bn

$\mathrm{R}^{2}=\mathrm{Ph}, m-\mathrm{ClC}_{6} \mathrm{H}_{4}, p-\mathrm{BrC}_{6} \mathrm{H}_{4}, p-\mathrm{ClC}_{6} \mathrm{H}_{4}, p-\mathrm{Tol}, n-\mathrm{Pr}$

Scheme 28. Michael reaction of aliphatic aldehydes and maleimides with catalyst 33 in the presence of ionic liquid-supported sulfonic acid 10 in brine.

The 3-alkylidene oxindole moiety is found in a range of biologically active products. Consequently, novel catalytic methodologies to prepare chiral $\gamma$-substituted alkylidene oxindoles are challenging. In this context, $\mathrm{Li}$ et al. recently developed enantioselective vinylogous Michael additions of various 3-alkylidene oxindoles to aromatic $\alpha, \beta$-unsaturated aldehydes performed in aqueous media [57]. As shown in Scheme 27, the reactions were catalyzed at $0{ }^{\circ} \mathrm{C}$ by $20 \mathrm{~mol} \%$ of chiral TBS-protected diphenylprolinol $\mathbf{3 2}$ in the presence of TEA as a base in a mixture of dichloromethane and brine as solvent. They led to a range of chiral functionalized $\gamma$ substituted alkylidene oxindoles as almost single $Z$-diastereomers $(Z / E>95: 5)$ with high enantioselectivities $(82-94 \%$ ee) and good yields (68-85\%) in most cases of substrates. However, a low yield $(16 \%)$ albeit combined with excellent stereoselectivities $(>90 \%$ de and $92 \%$ ee) was obtained in the reaction of a sterically hindered 3 alkylidene oxindole bearing a methoxy substituent at the 2-position of the phenyl ring $(\mathrm{R}=2-\mathrm{MeO})$. Moreover, in only one case of $\alpha, \beta$ unsaturated aldehydes, such as that bearing a para-methoxyphenyl substituent $\left(\mathrm{Ar}=o-\mathrm{MeOC}_{6} \mathrm{H}_{4}\right)$, the diastereoselectivity of the reaction was lower $(Z / E=87: 13)$.

In 2013, Headley and Qiao reported the use of a combination of diarylprolinol silyl ether-based organocatalyst $\mathbf{3 3}$ with ionic liquid- supported sulfonic acid $\mathbf{1 0}$ in enantioselective Michael additions of linear aliphatic aldehydes to maleimides performed in brine [58]. As shown in Scheme 28, the reactions yielded the corresponding chiral succinimide derivatives in moderate yields (15-76\%) and diastereoselectivities (34-80\% de), albeit with high enantioselectivities (86-96\% ee) in the absence of any organic solvent.

Michael-initiated asymmetric domino and tandem reactions of $\alpha, \beta$-unsaturated carbonyl compounds catalyzed by proline-derived organocatalysts in aqueous media have been recently developed. For example, Bradshaw and Bonjoch reported the enantioselective tandem Michael/cyclization/aza-Michael reaction occurring between a $\beta$-ketoester and a $\alpha, \beta$-unsaturated aldehyde in aqueous media [59]. As shown in Scheme 29, this process was catalyzed by diphenylprolinol silyl ether-based organocatalyst $\mathbf{3 4}$ in the presence of LiOAc as additive in water at room temperature to give, after treatment of the crude mixture with $\mathrm{LiOH}$ in aqueous isopropanol, the corresponding chiral functionalized morphans in moderate yields $(37-68 \%)$ and high enantioselectivities $(86-92 \%$ ee). The catalytic system was compatible with a wide range of $\beta$-ketoesters exhibiting both aliphatic and aromatic substituents.

Another organocatalytic Michael-initiated asymmetric tandem reaction performed in aqueous media was reported by Riguet and 


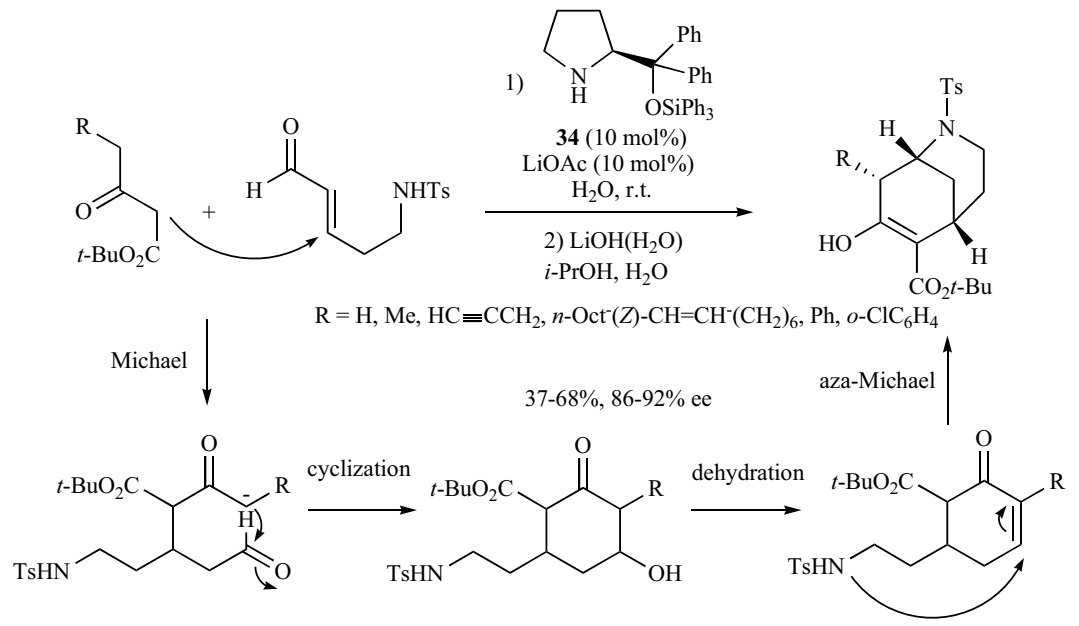

Scheme 29. Tandem Michael/cyclization/aza-Michael reaction with catalyst 34 in aqueous media.

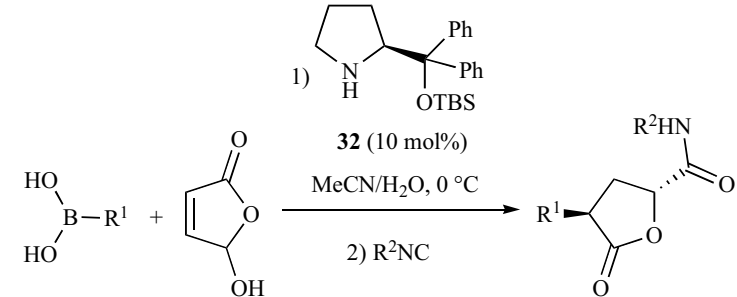<smiles>[R][Z]c1cc2cc([Y])ccc2n1C(=O)OC(C)(C)C</smiles><smiles>[R]=[R]c1ccc(C=C[Tl])cc1</smiles>

$$
\mathrm{R}^{2}=t-\mathrm{Bu}, \mathrm{Bn}, \mathrm{Cy}, p-\mathrm{MeOC}_{6} \mathrm{H}_{4} \mathrm{Ph}
$$

$\mathrm{R}^{3}=\mathrm{H}, \mathrm{OMe}:$

$73-76 \%, 56-61 \%$ de, $80-92 \%$ ee

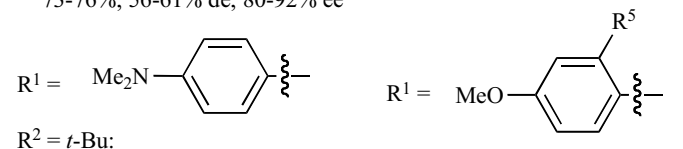

$\mathrm{R}^{2}=t-\mathrm{Bu}:$

$60 \%, 12 \%$ de, $76 \%$ ee

$$
\mathrm{R}^{1}=\mathrm{R}^{2}=t-\mathrm{Bu}
$$

$$
\mathrm{R}^{2}=t-\mathrm{Bu}, \mathrm{R}^{5}=\mathrm{H}, \mathrm{OMe}:
$$

$40-73 \%, 30-60 \%$ de, $16-64 \%$ ee

$84 \%, 50 \%$ de, $40 \%$ ee
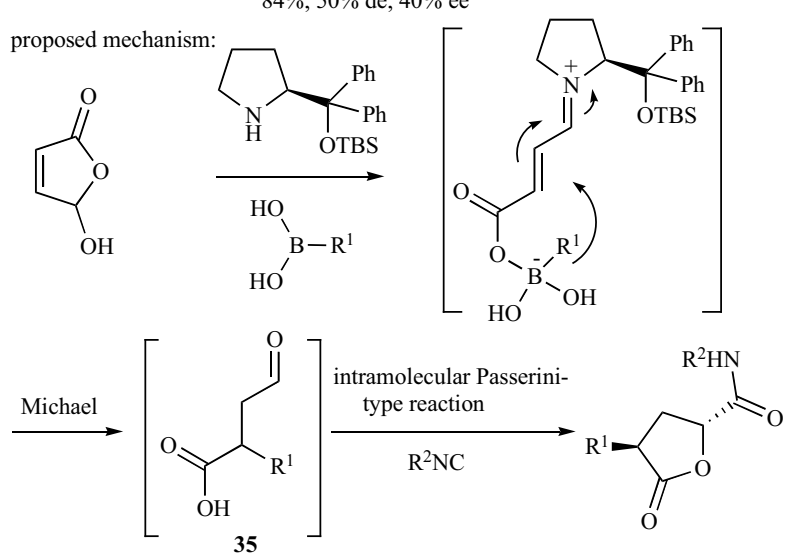

Scheme 30. Tandem Michael/Passerini-type reaction of boronic acids, 5hydroxyfuran-2 $(5 H)$-one and isonitriles with catalyst $\mathbf{3 2}$ in aqueous media.

Bos, in 2014 [60]. It involved in a first step the Michael addition of a boronic acid to 5-hydroxyfuran-2 $(5 H)$-one catalyzed by chiral
TBS-protected diphenylprolinol $\mathbf{3 2}$ in aqueous acetonitrile as solvent, leading to intermediate 35 (Scheme 30). After addition of an isonitrile, the latter underwent an intramolecular Passerini-type reaction to afford the corresponding $\gamma$-substituted lactone in moderate to good yield (40-84\%) and low to high enantioselectivity (16$92 \%$ ee). The best results were achieved by using $N$-Boc-indole-2boronic acids since the corresponding chiral $\alpha$-indole- $\gamma$-substituted lactones were obtained in uniformly good yields (73-76\%) and enantioselectivities $(80-92 \%$ ee) in combination with moderate diastereoselectivities $(56-61 \% \mathrm{de})$. On the other hand, lower enantioselectivities (16-84\% ee) were observed by using other boronic acids, including styrenes, electron-rich phenyl rings and heteroaromatic derivatives, in spite of moderate to good yields (40-84\%), as summarized in Scheme 30.

\subsection{With Other Organocatalysts}

The asymmetric sulfa-Michael addition of thiols to $\alpha, \beta$ unsaturated carbonyl compounds is a simple methodology to prepare valuable chiral sulfur-containing compounds [61]. In 2016, Kalaria et al. demonstrated that chiral cinchonidinium bromide catalyst 36 catalyzed the Michael addition of thiols to various types of $\alpha, \beta$-unsaturated carbonyl compounds in water [62]. As shown in Scheme 31, the reactions were performed with $6 \mathrm{~mol} \%$ of this organocatalyst in combination with $20 \mathrm{~mol} \%$ of tetra- $n$-butyl ammonium fluoride as additive at room temperature without using any organic solvents. In all cases of substrates including $\alpha, \beta$ unsaturated carboxylic acids, esters, and ketones, the corresponding chiral sulfides were achieved in uniformly excellent enantioselectivities (91->99\% ee) and high yields (79-98\%). Two types of thiols, such as para-chlorobenzenethiol and benzyl mercaptan, were tolerated by the catalyst system, although the enantioselectivities obtained in the reaction of the latter substrate were found generally slightly lower than those achieved by using the former reagent.

On the other hand, only few examples of asymmetric 1,6conjugate additions of sulfur nucleophiles have been developed [2a]. Among them, a highly enantioselective 1,6-conjugate addition of thioacetic acid to para-quinone methides was recently developed by Li et al. by using chiral phosphoric acid catalysis in aqueous media [63]. Indeed, para-quinone methides are known to be highly efficient vinylogous Michael acceptors in 1,6-conjugate additions. Since the first enantioselective organocatalytic version reported by Fan et al. in 2013 [64], a number of these reactions have been successfully developed [2a, 65]. As shown in Scheme 32, the reaction 


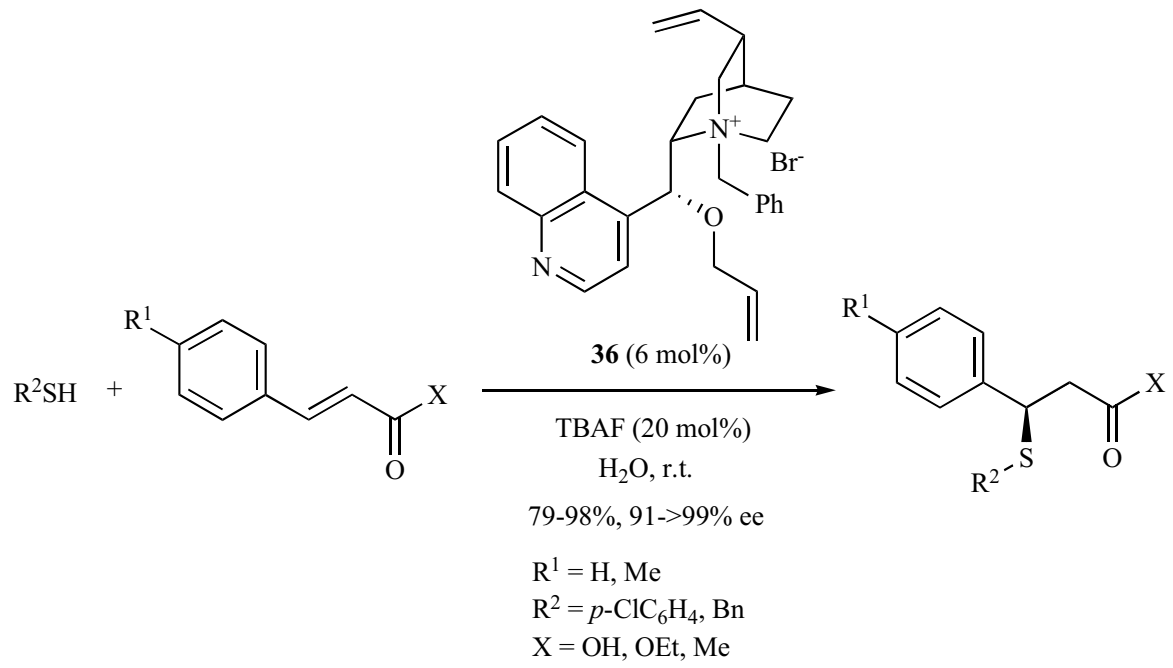

Scheme 31. Michael reaction of thiols and $\alpha, \beta$-unsaturated carbonyl compounds with cinchonidinium bromide catalyst $\mathbf{3 6}$ in water.

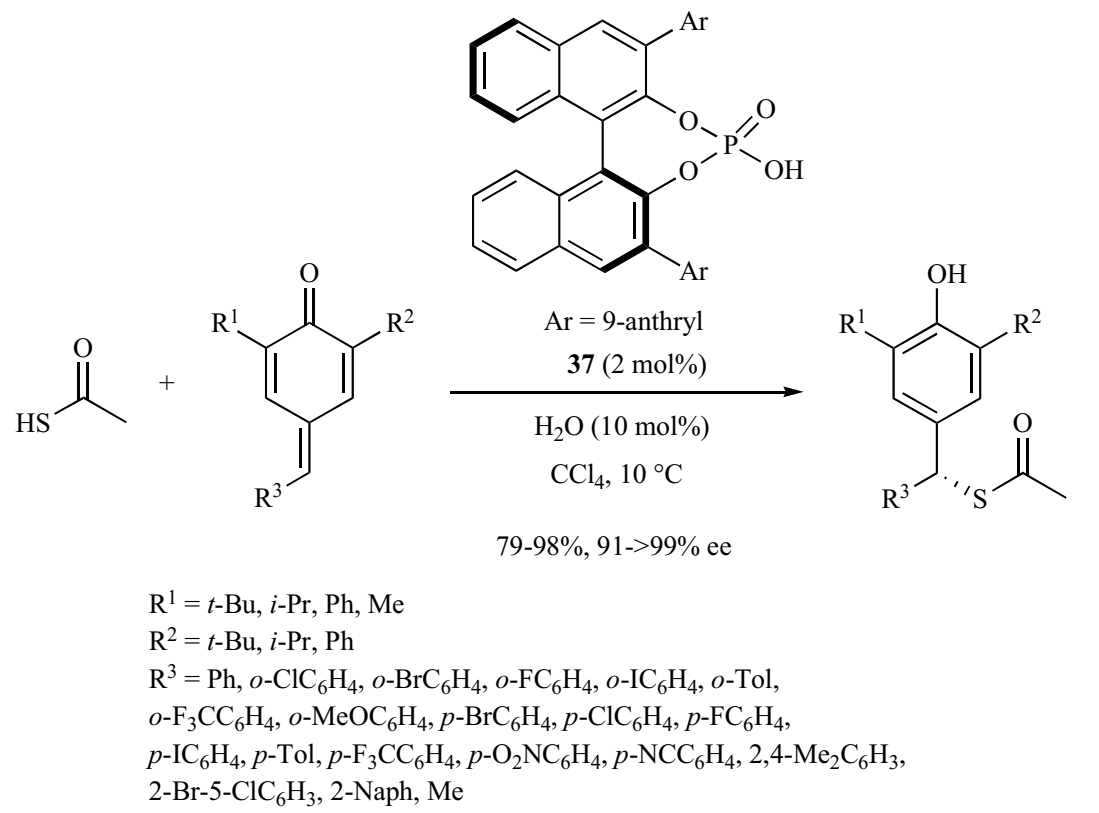

Scheme 32. 1,6-Conjugate addition of thioacetic acid and para-quinone methides with phosphoric acid catalyst $\mathbf{3 7}$ in aqueous media.

was promoted by only $2 \mathrm{~mol} \%$ of chiral phosphoric acid 37 in the presence of $10 \mathrm{~mol} \%$ of water in tetrachloromethane at $10{ }^{\circ} \mathrm{C}$, leading to the corresponding chiral sulfur-containing products in uniformly excellent enantioselectivities ( $91->99 \%$ ee) and high yields (79-98\%). The authors demonstrated that the presence of water was essential for the stereocontrol of the reactions. This was confirmed by theoretical calculations, showing a stabilization of the transition state through an unprecedented $\mathrm{O}-\mathrm{H}^{\cdots}{ }^{\prime} \pi$ interaction between water and the aromatic nucleus of the catalyst.

Finally, resin-supported peptide catalyst $\mathbf{3 8}$ was designed and applied by Kudo et al. to promote the enantioselective Michael addition of nitromethane to $\alpha, \beta$-unsaturated ketones in aqueous media [66]. As shown in Scheme 33, the process was performed in the presence of benzoic acid as additive at $40{ }^{\circ} \mathrm{C}$ in aqueous THF, providing the corresponding chiral Michael products in good yields $(69-80 \%)$ and excellent enantioselectivities $(90-96 \%$ ee) regardless of the nature of the substituents of the $\alpha, \beta$-unsaturated ketones. Moreover, the solid catalyst could be easily recovered by filtration and reused, but its catalytic activity gradually decreased after three cycles. This peptide-supported catalyst was also found active in enantioselective Michael additions of malonates to $\alpha, \beta$-unsaturated ketones, leading under similar reaction conditions but without the presence of additive to the corresponding chiral products in moderate to high yields $(50-87 \%)$ and uniformly excellent enantioselectivities $(94-97 \%$ ee). Even a cyclic $\alpha, \beta$-unsaturated ketone, such as cyclohexenone, was compatible to the process, providing the desired product in both high yield (85\%) and enantioselectivity $(94 \%$ ee), as shown in Scheme 33.

\section{CONCLUSION}

From a green chemistry perspective, the development of enantioselective organocatalytic reactions in aqueous media has become one of the most challenging areas of organic chemistry. Many efforts have been made in this field in the past few years, taking advantage that organocatalysts are tolerant to air and moisture, thus allowing their use under aqueous conditions and to the fact that hydrogen bonding playing a decisive role in organocatalysis is en- 


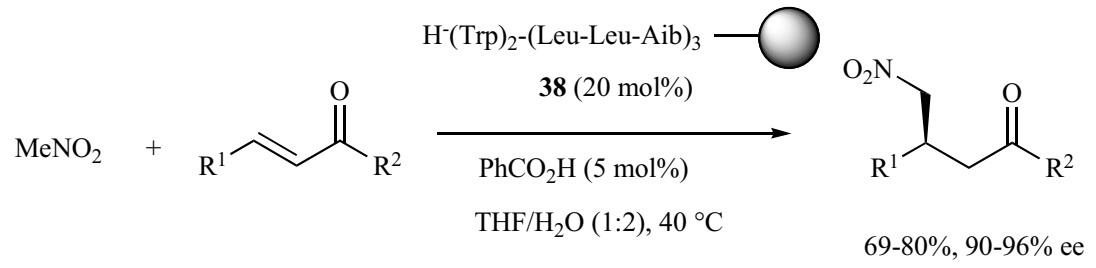

$\mathrm{R}^{1}=\mathrm{Ph}, p-\mathrm{O}_{2} \mathrm{NC}_{6} \mathrm{H}_{4}, p-\mathrm{F}_{3} \mathrm{CC}_{6} \mathrm{H}_{4}, p-\mathrm{ClC}_{6} \mathrm{H}_{4}, p-\mathrm{BrC}_{6} \mathrm{H}_{4}$, $p$ - $\mathrm{MeOC}_{6} \mathrm{H}_{4}, 2-\mathrm{Naph}, \mathrm{BnCH}_{2}$

$\mathrm{R}^{2}=\mathrm{Me}, \mathrm{Et}, n-\mathrm{Pr}$<smiles>[R10]OC(=O)CC(=O)O[Z10]</smiles><smiles>[R]C=CC(C)=O</smiles><smiles>O=C(CC(=O)OCc1ccccc1)OCc1ccccc1</smiles><smiles>O=C1C=CCCC1</smiles>

38 (20 mol\%)

$\mathrm{THF} / \mathrm{H}_{2} \mathrm{O}(1: 2), 40{ }^{\circ} \mathrm{C}$

$$
\begin{aligned}
& \mathrm{R}^{1}=\mathrm{Me}, \mathrm{Bn} \\
& \mathrm{R}^{2}=p-\mathrm{O}_{2} \mathrm{NC}_{6} \mathrm{H}_{4}, n-\mathrm{Bu}
\end{aligned}
$$<smiles>[R]OC(=O)C(C([R2])=O)C([R])CC(C)=O</smiles>

$50-87 \%, 94-97 \%$ ee

same conditions<smiles>O=C1CCC[C@H](C(C(=O)O)C(=O)OCc2ccccc2)C1</smiles>

$85 \%, 94 \%$ ee

Scheme 33. Michael reactions of nitromethane and malonates with $\alpha, \beta$-unsaturated ketones with resin-supported peptide $\mathbf{3 8}$ in aqueous media.

hanced in the presence of water. Especially, a number of highly efficient enantioselective organocatalytic Michael reactions performed in water or in aqueous media have been recently developed. This review demonstrates that today many types of chiral organocatalysts, including proline-derivatives, 1,2-diamines, cinchona alkaloids, peptides, phosphoric acids, as well as supported organocatalysts, are capable to highly efficiently promote enantioselective Michael reactions in pure water or aqueous media. Many of these reactions involve asymmetric conjugate additions of aldehydes, ketones, or 1,3-dicarbonyl compounds to nitroalkenes performed with uniformly high yields and enantioselectivities of up to $>99 \%$ ee. $\alpha, \beta$-Unsaturated carbonyl compounds, such as enones, enals, maleimides, and para-quinone methides, among others, have also been successfully submitted to aqueous Michael additions with various types of nucleophiles, including aldehydes, ketones, 1,3dicarbonyl compounds, 4-hydroxycoumarins, nitromethane, 3alkylidene oxindoles, thiols and thioacetic acid, allowing remarkable enantioselectivities of up to $>99 \%$ ee to be achieved.

In the near future, a deeper understanding of the exact role of water in organocatalytic asymmetric Michael additions will be indispensable to help the design of even more active and enantioselective novel organocatalysts. Indeed, in addition to be a green solvent, water plays a central role in increasing the efficiency and stereoselectivity of organocatalysts by giving them special properties ranging from their participation to the mechanism of the reaction to the establishment of physical properties, such as the generation of emulsions or hydrophobic interactions, required to achieve stereocontrol.
[1] (a) Komnenos, T. Fettaldehyden auf Malonsäure und Aethylmalonat. Justus Liebigs Ann. Chem., 1883, 218, 145-169. (b) Perlmutter, P. In: Conjugate Addition Reactions in Organic Synthesis, Pergamon Press: Oxford, 1992. (c) Sibi, M.P.; Manyem, S. Enantioselective conjugate additions. Tetrahedron, 2000, 56, 8033-8061. (d) Kanai, M.; Shibasaki, M. In: Catalytic Asymmetric Synthesis, 2nd ed., Wiley: New York, 2000, p. 569. (e) Krause, N.; Hoffmann-Roder, A. Recent advances in catalytic enantioselective Michael additions. Synthesis, 2001, 171-196. (f) Berner, O.M.; Tedeschi, L.; Enders, D. Asymmetric Michael additions to nitroalkenes. Eur.J. Org. Chem., 2002, 1877-1894. (g) Ballini, R.; Bosica, G.; Fiorini, D.; Palmieri, A.; Petrini, M. Conjugate additions of nitroalkanes to electron-poor alkenes: Recent results. Chem. Rev., 2005, 105, 933-971. (h) Bhanja, C.; Jena, S.; Nayak, S.; Mohapatra, S. Organocatalytic tandem Michael addition reactions: A powerful access to the enantioselective synthesis of functionalized chromenes, thiochromenes and 1,2-dihydroquinolines. Belstein J. Org. Chem., 2012, 8, 1668-1694.

[2] (a) Chauhan, P.; Kaya, U.; Enders, D. Advances in organocatalytic 1,6addition reactions: enantioselective construction of remote stereogenic centers. Adv. Synth. Catal., 2017, 359, 888-912. (b) Phillips, A.M.F. Organocatalytic asymmetric nitro-Michael reactions. Curr. Org. Synth, 2016, 13, 687-725. (c) Nayak, S.; Panda, P.; Bhakta, S.; Mishra, S.K.; Mohapatra, S. 
Current advances of organocatalytic Michael-Michael cascade reaction in the synthesis of highly functionalized cyclic molecules. RSC $A d v$., 2016, 6, 96154-96175. (d) Alonso, D.A. In: Enantioselective Organocatalyzed Reactions II. Asymmetric C-C Bond Formation Processes, Mahrwald, R., Ed.; Wiley-VCH: Weinheim; 2013, p. 41. (e) Rios, R.; Companyo, X. In: Comprehensive Enantioselective Organocatalysis: Catalysis, Reactions and Applications, Dalko, P.I., Ed.; Wiley-VCH: Weinheim, 2013, Vol. III, p. 977. (f) Aitken, L.S.; Arezki, N.R.; Dell'Isola, A.; Cobb, A.J.A. Asymmetric organocatalysis and the nitro group functionality. Synthesis, 2013, 45, 26272648. (g) Sanchez-Rosello, M.; Acena, J.L.; Simon-Fuentes, A.; del Pozo, C. A general overview of the organocatalytic intramolecular aza-Michael reaction. Chem. Soc. Rev., 2014, 43, 7430-7453. (h) Roca-Lopez, D.; Sadaba, D.; Delso, I.; Herrera, R. P.; Tejero, T.; Merino, P. Asymmetric organocatalytic synthesis of $\gamma$-nitrocarbonyl compounds through Michael and Domino reactions. Tetrahedron: Asymmetry, 2010, 21, 2561-2601. (i) Enders, D.; Wang, C.; Liebich, J.X. Organocatalytic asymmetric Aza-Michael additions. Chem. Eur. J., 2009, 15, 11058-11076. (j) Vicario, J.L.; Badia, D.; Carrillo, L. Organocatalytic enantioselective Michael and hetero-Michael reactions. Synthesis, 2007, 14, 2065-2092. (k) Almasi, D.; Alonso, D.A.; Najera, C. Organocatalytic asymmetric conjugate additions. Tetrahedron: Asymmetry, 2007, 18, 299-365. (1) Tsogoeva, S.B. Recent advances in asymmetric organocatalytic 1,4-conjugate additions. Eur. J. Org. Chem., 2007, 1701-1716. (m) Erkkila, A.; Majander, I.; Pihko, P.M. Iminium catalysis. Chem. Rev., 2007, 107, 5416-5470. (n) Mukherjee, S.; Yang, J.W.; Hoffmann, S.; List, B. Asymmetric enamine catalysis. Chem. Rev., 2007, 107, 5471-5569.

For general reviews on organic synthesis in water, see: (a) Lindstrom, U.M. Stereoselective organic reactions in water. Chem. Rev., 2002, 102, 2751-2772. (b) Li, C.J. Organic reactions in aqueous media with a focus on carbon-carbon bond formations: A decade update. Chem. Rev., 2005, 105, 3095-3166. (c) Li, C.J.; Chen, L. Organic chemistry in water. Chem. Soc Rev., 2006, 35, 68-82. (d) Lindstrom, U.M. Organic Reaction in Water: Principles, Strategies and Applications, Blackwell Publishing: Oxford, 2007. (e) Mase, N.; Barbas, C.F. In water, on water, and by water: Mimicking nature's aldolases with organocatalysis and water. Org. Biomol. Chem., 2010, 8, 4043-4050. (f) Bhowmick, S.; Bhowmick, K.C. Catalytic asymmetric carbon-carbon bond-forming reactions in aqueous media. Tetrahedron: Asymmetry, 2011, 22, 1945-1979. (g) Kobayashi, S. Science of Synthesis: Water in Organic Synthesis, Thieme: Stuttgart/New York, 2012. (h) Simon, M.O.; Li, C.J. Green chemistry oriented organic synthesis in water. Chem. Soc. Rev. 2012, 41, 1415-1427. (i) Giacalone, F.; Gruttadauria, M. In: Comprehensive Enantioselective Organocatalysis: Catalysts, Reactions and Applications, Dalko, P. I., Ed.; Wiley-VCH: Weinheim, 2013, Vol. III, p. 673.

[4] Chen, F.; Gong, P.; Gao, Y.; Zhang, H.; Zhou, A. Asymmetric organocatalytic Michael additions in aqueous media. Mini-Rev. Org. Chem., 2013, 10, 207-216.

[5] Guillena, G.; Alonso, D.; Baeza, A.; Chinchilla, R.; Flores-Ferràndiz, J.; Gomez-Martinez, M.; Trillo, P. Pursuing chemical efficiency by using supported organocatalysts for asymmetric reactions under aqueous conditions. Current Organocatalysis, 2015, 2, 102-123.

[6] Jimeno, C. Water in asymmetric organocatalytic systems: A global perspective. Org. Biomol. Chem., 2016, 14, 6147-6164.

[7] (a) Pan, C.; Wang, Z. Catalytic asymmetric formation of carbon-carbon bond in the presence of water. Coord. Chem. Rev., 2008, 252, 736-750. (b) Raj, M.; Singh, V.K. Organocatalytic reactions in water. Chem. Commun., 2009, 6687-6703. (c) Gruttadauria, M.; Giacalone, F.; Noto, R. Water in stereoselective organocatalytic reactions. Adv. Synth. Catal., 2009, 351, $33-$ 57.

[8] Klijn, J.E.; Engberts, J.B.F.N. Organic chemistry: Fast reactions 'on water'. Nature, 2005, 435, 746-747.

[9] Rideout, D.C.; Breslow, R. Hydrophobic acceleration of Diels-Alder reactions. J. Am. Chem. Soc., 1980, 102, 7816-7817.

[10] Narayan, S.; Muldoon, J.; Finn, M.G.; Fokin, V.V.; Kolb, H.C.; Sharpless, K.B. "On water": Unique reactivity of organic compounds in aqueous suspension. Angew. Chem., Int. Ed., 2005, 44, 3275-3279.

[11] Hayashi, H. In water or in the presence of water? Angew. Chem., Int. Ed., 2006, 45, 8013-8104

[12] Blackmond, D.G.; Armstong, A.; Coombe, V.; Wells, A. Water in organocatalytic processes: Debunking the myths. Angew. Chem., Int. Ed., 2007, 46, 3798-3800

[13] Mase, N.; Watanabe, K.; Yoda, H.; Takabe, K.; Tanaka, F.; Barbas, C.F. Organocatalytic direct Michael reaction of ketones and aldehydes with $\beta$ Nitrostyrene in brine. J. Am. Chem. Soc., 2006, 128, 4966-4967.

[14] Luo, S.Z.; Mi, X.; Liu, S.; Cheng, J.P. Surfactant-type asymmetric organocatalyst: Organocatalytic asymmetric Michael addition to nitrostyrenes in water. Chem. Commun., 2006, 35, 3687-3689.

[15] (a) Zu, L.; Wang, J.; Li, H.; Wang, W. A recyclable fluorous $(S)$-pyrrolidine sulfonamide promoted direct, highly enantioselective Michael addition of ketones and aldehydes to nitroolefins in water. Org. Lett., 2006, 8, 30773079. (b) Yan, Z.Y.; Niu, Y.N.; Wei, H.L.; Wu, L.Y.; Zhao, Y.B.; Liang, Y.M. Combining proline and 'click chemistry': A class of versatile organocatalysts for the highly diastereo- and enantioselective Michael addition in water. Tetrahedron: Asymmetry, 2006, 17, 3288-3293. (c) Carlone, A.; Marigo, M.; North, C.; Landa, A.; Jørgensen, K.A. A simple asymmetric organocatalytic approach to optically active cyclohexenones. Chem. Com- mun., 2006, 4928-4930. (d) Cao, Y.J.; Lai, Y.Y.; Wang, X.; Li, Y.J.; Xiao, W.J. Michael additions in water of ketones to nitroolefins catalyzed by readily tunable and bifunctional pyrrolidine-thiourea organocatalysts. Tetrahedron Lett., 2007, 48, 21-24. (e) Alza, E.; Cambeiro, X.C.; Jimeno, C.; Pericas, M.A. Highly enantioselective Michael additions in water catalyzed by a PS-supported pyrrolidine. Org. Lett., 2007, 9, 3717-3720. (f) Singh, V.; Singh, V.K. Highly enantioselective water-compatible organocatalyst for Michael reaction of ketones to nitroolefins. Org. Lett., 2007, 9, 1117-1119. (g) Palomo, C.; Landa, A.; Mielgo, A.; Oiarbide, M.; Puente, S.; Vera, S. Water-compatible iminium activation: Organocatalytic Michael reactions of carbon-centered nucleophiles with enals. Angew. Chem., Int. Ed., 2007, 46, 8431-8435. (h) Guizzetti, S.; Benaglia, L.; Raimondi, G.; Celentano, G. Enantioselective direct aldol reaction "on Water" promoted by chiral organic catalysts. Org. Lett., 2007, 9, 1247-1250. (i) Zhu, S.; Yu, S.; Ma, D. Highly efficient catalytic system for enantioselective Michael addition of aldehydes to nitroalkenes in water. Angew. Chem., Int. Ed., 2008, 47, 545-548. (j) Belot, S.; Massaro, A.; Tenti, A.; Mordini, A.; Alexakis, A. Enantioselective organocatalytic conjugate addition of aldehydes to nitrodienes. Org. Lett., 2008, 10, 4557-4560. (k) Ma, A.; Zhu, S.; Ma, D. Enantioselective organocatalytic Michael addition of malonates to $\alpha, \beta$-unsaturated aldehydes in water. Tetrahedron Lett., 2008, 49, 3075-3077. (1) Lu, J.; Liu, F.; Loh, T.P. Enantioselective Michael addition of dicyanoolefins to $\alpha, \beta$-unsaturated aldehydes in aqueous medium. Adv. Synth. Catal., 2008, 350, 1781-1784. (m) Bukuo Ni, J.W.; Headley, A.D. Di(methylimidazole)prolinol silyl ether catalyzed highly Michael addition of aldehydes to nitroolefins in water. Org. Lett., 2009, 11, 3354-3356. (n) Zheng, Z.; Perkins, B.L.; Ni, B. Organocatalytic enantioselective Michael addition of $\beta$-diketones to $\beta$ nitrostyrene: The first Michael addition of dipivaloylmethane to an activated olefin. J. Am. Chem. Soc., 2010, 132, 50-51. (o) Chandrasekhar, S.; Kumar, T.P.; Haribabu, K.; Reddy, C.R. Hydroxyphthalimide allied triazolepyrrolidine catalyst for asymmetric Michael additions in water. Tetrahedron: Asymmetry, 2010, 21, 2372-2375. (p) Syu, S.E.; Kao, T.T.; Lin, W.W.A. A new type of organocatalyst for highly stereoselective Michael addition of ketones to nitroolefins on water. Tetrahedron, 2010, 66, 891-897. (q) Mokgweetsi, P.; Botlhole, L.; Singh, G.S. Recent progress in asymmetric aldol reactions under solvent-free conditions or in aqueous medium. Curr. Green Chem., 2016, 3, 318-327.

[16] Wei, J.; Guo, W.; Zhang, B.; Liu, Y.; Du, X.; Li, C. An amphiphilic organic catalyst for the direct asymmetric Michael addition of cycloketone to nitroolefins in water. Chin. J. Catal., 2014, 35, 1008-1011.

[17] Zhang, H.; Yan, X. Efficient enantioselective Michael addition of nitroalkenes catalyzed by a new surfactant-type thiourea organocatalyst in water. $A d v$. Mater. Res., 2014, 1015, 602-605.

[18] Wang, Z.Y.; Ban, S.R.; Yang, M.C.; Li, Q.S. Highly enantioselective Michael addition of cyclohexanone to nitroolefins catalyzed by pyrrolidinebased bifunctional benzoylthiourea in water. Chirality, 2016, 28, 721-727.

[19] Zhao, H.W.; Yang, Z.; Yue, Y.Y.; Li, H.L.; Song, X.Q.; Sheng, Z.H.; Meng, W.; Guo, X.Y. Asymmetric direct Michael reactions of cyclohexanone with aromatic nitroolefins in water catalyzed by novel axially unfixed biarylbased bifunctional organocatalysts. Synlett, 2014, 25, 293-297.

[20] Kumar, T.P.; Radhika, L.; Haribabu, K.; Kumar, V.N. Pyrrolidineoxyimides: New chiral catalysts for enantioselective Michael addition of ketones to nitroolefins in water. Tetrahedron: Asymmetry, 2014, 25, 1555-1560.

[21] Kumar, T.P.; Prasad, S.S.; Haribabu, K.; Kumar, V.N.; Reddy, C.S. Pyrrolidine-HOBt: An oxytriazole catalyst for the enantioselective Michael addition of cyclohexanone to nitroolefins in water. Tetrahedron: Asymmetry, 2016, 27, 1133-1138.

[22] Kumar, T.P.; Sattar, M.A.; Prasad, S.S.; Haribabu, K.; Reddy, C.S. Enantioselective Michael addition of aldehydes to nitroolefins catalyzed by pyrrolidine-HOBt. Tetrahedron: Asymmetry, 2017, 28, 401-409.

[23] Qiao, Y.; Headley, A.D. Ionic liquid immobilized organocatalysts for asymmetric reactions in aqueous media. Catalysts, 2013, 3, 709-725.

[24] Ghosh, S.K.; Qiao, Y ; Ni, B.; Headley, A.D. Asymmetric Michael reaction catalyzed by a highly efficient and recyclable organocatalysts in aqueous media. Org. Biomol. Chem., 2013, 11, 1801-1804.

[25] Chen, Q.; Qiao, Y.; Ni, B. Highly enantioselective organocatalytic Michael addition of ketones to nitroolefins in the presence of water. Synlett, 2013, 24, 839-842.

[26] Suzuki, N.; Akebi, R.; Inoue, T.; Rikukawa, M.; Masuyama, Y. Asymmetric aldol and michael reactions in water using organocatalysts immobilized on a thermoresponsive "Linear" block copolymer. Current Organocatalysis, 2016, 3, 306-314

[27] Du, J.; Shuai, B.; Tao, M.; Wang, G.; Zhang, W. Pyrrolidine modified PANF catalyst for asymmetric Michael addition of ketones to nitrostyrenes in aqueous phase. Green Chem., 2016, 18, 2625-2631

[28] Hayashi, Y.; Mukaiyama, T.; Benohoud, M.; Gupta, N.R.; Ono, T.; Toda, S. ${ }^{16} \mathrm{O} /{ }^{18} \mathrm{O}$ Exchange of aldehydes and ketones caused by $\mathrm{H}_{2}{ }^{18} \mathrm{O}$ in the mechanistic investigation of organocatalyzed Michael, Mannich, and Aldol Reactions. Chem. Eur. J., 2016, 22, 5868-5872.

[29] (a) Lalonde, M.P.; Chen, Y.; Jacobsen, E.N. A chiral primary amine thiourea catalyst for the highly enantioselective direct conjugate addition of alpha,alpha-disubstituted aldehydes to nitroalkenes. Angew. Chem., Int. Ed., 2006, 45, 6366-6370. (b) Yalalov, D.A.; Tsogoeva, S.B.; Schmatz, S. Chiral Thiourea-based bifunctional organocatalysts in the asymmetric nitro-Michael addition: A joint experimental-theoretical study. Adv. Synth. Catal., 2006, 
348, 826-832. (c) Wei, S.; Yalalov, D.A.; Tsogoeva; Schmatz, S. New highly enantioselective thiourea-based bifunctional organocatalysts for nitroMichael addition reactions. Catal. Today, 2007, 121, 151-157. (d) Xue, F.; Zhang, S.; Duan, W.; Wang, W. A novel bifunctional sulfonamide primary amine-catalyzed enantioselective conjugate addition of ketones to nitroolefins. Adv. Synth. Catal., 2008, 350, 2194-2198. (e) Mao, Z.F.; Jia, Y.M.; Li, W.Y.; Wang, R. Water-compatible iminium activation: Highly enantioselective organocatalytic Michael addition of malonates to $\alpha, \beta$ unsaturated enones. J. Org. Chem., 2010, 75, 7428-7430. (f) Günler, Z.I.; Companyo, X.; Alfonso, I.; Burés, J.; Jimeno, C.; Pericas, M.A. Deciphering the roles of multiple additives in organocatalyzed Michael additions. Chem. Commun., 2016, 52, 6821-6824.

[30] Avila, A.; Chinchilla, R.; Fiser, B.; Gomez-Bengoa, E.; Najera, C. Enantioselective Michael addition of isobutyraldehyde to nitroalkenes organocatalyzed by chiral primary amine-guanidines. Tetrahedron: Asymmetry, 2014, 25, 462-467.

[31] Rogozinska-Szymczak, M.; Mlynarski, J. Unmodified primary amine organocatalysts for asymmetric Michael Reactions in aqueous media. Eur. J.Org. Chem., 2015, 6047-6051.

[32] Garcia-Garcia, P.; Moreno, J.M.; Diaz, U.; Bruix, M.; Corma, A. Organicinorganic supramolecular solid catalyst boosts organice reactions in water Nat. Commun., 2016, 7, 10835-10843.

[33] Tukhvatshin, R.S.; Kucherenko, A.S.; Nelyubina, Y.V.; Zlotin, S.G. Tertiary amine-derived ionic liquid-supported squaramide as a recyclable organocatalyst for noncovalent "On Water" catalysis. ACS Catal., 2017, 7, 2981-2989.

[34] Chen, F.X.; Shao, C.; Wang, Q.; Gong, P.; Zhang, D.Y.; Zhang, B.Z.; Wang, R. An enantioselective Michael addition of malonate to nitroalkenes catalyzed by low loading demethylquinine salts in water. Tetrahedron Lett., 2007, 48, 8456-8459.

[35] Chen, F.X.; Shao, C.; Liu, Q.; Gong, P.; Liu, C.L.; Wang, R. Asymmetric Michael addition of trisubstituted carbanion to nitroalkenes catalyzed by sodium demethylquinine salt in water. Chirality, 2009, 21, 600-603.

[36] Bae, H.Y.; Song, C.E. Unprecedented hydrophobic amplification in noncovalent organocatalysis « on Water »: Hydrophobic chiral squaramide catalyzed Michael addition of malonates to nitroalkenes. ACS $A d v$., 2015, 5, 36133619

[37] Sim, J.H.; Song, C.E. Water-enabled catalytic asymmetric Michael reactions of unreactive nitroalkenes: one-pot synthesis of chiral GABA-analogs with all-carbon quaternary stereogenic centers. Angew. Chem., Int. Ed., 2017, 56, $1835-1839$.

[38] Xu, X.; Cheng, T.; Liu, X.; Xu, J.; Jin, R.; Liu, G. Chiral squaramidefunctionalized imidazolium-based organic-inorganic hybrid silica promotes asymmetric Michael addition of 1,3-dicarbonyls to nitroalkenes in brine. ACS Catal., 2014, 4, 2137-2142.

[39] Zhang, K.; An, J.; Su, Y.; Zhang, J.; Wang, Z.; Cheng, T.; Liu, G. Amphiphilic hyperbranched polyethoxysiloxane: A self-templating assembled platform to fabricate functionalized mesostructured silicas for aqueous enantioselecive reactions. ACS Catal., 2016, 6, 6229-6235.

[40] Colby Davie, E.A.; Mennen, S.M.; Xu, Y.; Miller, S.J. Asymmetric catalysis mediated by synthetic peptides. Chem. Rev., 2007, 107, 5759-5812.

[41] Xu, Y.; Zou, W.; Sunden, H.; Ibrahem, I.; Cordova, A. Small peptidecatalyzed enantioselective addition of ketones to nitroolefins. Adv. Synth Catal., 2006, 348, 418-424.

[42] Duschmalé, J.; Kohrt, S.; Wennemers, H. Peptide catalysis in aqueous emulsions. Chem. Commun., 2014, 50, 8109-8112.

[43] (a) Bayat, S.; Tejo, B.A.; Abdulmalek, E.; Yahya, N.M.; Salleh, A.B.; Rahman, M.B.A. Enantioselectivity investigation of short polar peptides with different positions in the Michael reaction. Synth. Commun., 2013, 2013, 2725-2732. (b) Bayat, S.; Abdulmalek, E.; Tejo, B.A.; Salleh, A.B.; Normi, Y.M.; Rahman, M.B.A. Novel octapeptide as an asymmetric catalyst for Michael reaction in aqueous media. Synth. Commun., 2013, 43, 3130-3140.

[44] Chandrasekhar, S.; Kumar, C.P.; Kumar, T.P.; Haribabu, K.; Jagadeesh, B.; Lakshmi, J.K.; Mainkar, P.S. Peptidomimetic organocatalysts : Efficient Michael addition of ketones onto nitroolefins with very low catalyst loading. RSC Adv., 2014, 4, 30325-30331.

[45] Kamito, Y; Masuda, A.; Yuasa, H.; Tada, N.; Itoh, A.; Nakashima, K.; Hirashima, S.I.; Koseki, Y.; Miura, T. Asymmetric conjugate addition of malonate to $\alpha, \beta$-unsaturated ketones in water using a perfluoroalkanesulfonamide organocatalyst. Tetrahedron: Asymmetry, 2014, 25, 974-979.

[46] Rogozinska-Szymczak, M.; Mlynarski, J. Asymmetric synthesis of warfarin and its analogues on water. Tetrahedron: Asymmetry, 2014, 25, 813-820.

[47] Jahdav, A.P.; Bhaskara Rao, V.U.; Singh, P.; Gonnage, R.G.; Singh, R.P. Asymmetric vinylogous Michael reaction of cyclic enones with silyloxy furans. Chem. Commun., 2015, 51, 13941-13944.

[48] Liu, W.X.; Chen, S.K.; Tian, J.M.; Tu, Y.Q.; Wang, S.H.; Zhang, F.M. A triazole organocatalyst with spiropyrrolidine framework and its application to the catalytic asymmetric addition of nitromethane to $\alpha, \beta$-unsaturated aldehydes. Adv. Synth. Catal., 2015, 357, 3831-3835.

[49] Avila, A.; Chinchilla, R.; Gomez-Bengoa, E.; Najera, C. Enantioselective synthesis of succinimides by Michael Addition of aldehydes to maleimides organocatalyzed by Chiral Primary Amine-Guanidines. Eur. J. Org. Chem., 2013, 5085-5092.

[50] Avila, A.; Chinchilla, R.; Gomez-Bengoa, E.; Najera, C. Enantioselective Michael addition of aldehydes to maleimides organocatalyzed by chiral 1,2- diamines: An experimental and theoretical study. Tetrahedron: Asymmetry, 2013, 24, 1531-1535.

[51] Vizcaino-Milla, P.; Sansano, J.M.; Najera, C.; Fiser, B.; Gomez-Bengoa, E. Primary amine-2-aminopyrimidine chiral organocatalysts for the enantioselective conjugate addition of branched aldehydes to maleimides. Synthesis, 2015, 47, 2199-2206.

[52] (a) Posner, G.H. Multicomponent one-pot annulations forming 3 to 6 bonds. Chem. Rev., 1986, 86, 831-844. (b) Ho, T.L. In: Tandem Organic Reactions Wiley: New York; 1992. (c) Tietze, L.F.; Beifuss, U. Sequential transformations in organic chemistry: A synthetic strategy with a future. Angew. Chem., Int. Ed., 1993, 32, 131-163. (d) Bunce, R.A. Recent advances in the use of tandem reactions for organic synthesis. Tetrahedron, 1995, 51 , 13103-13159. (e) Tietze, L.F. Domino reactions in organic synthesis. Chem. Rev., 1996, 96, 115-136. (f) Parsons, P.J.; Penkett, C.S.; Shell, A.J. Tandem reactions in organic synthesis: Novel strategies for natural product elaboration and the development of new synthetic methodology. Chem. Rev., 1996, 96, 195-206. (g) Tietze, L.F.; Rackelmann, N. Domino reactions in the synthesis of heterocyclic natural products and analogs. Pure Appl. Chem., 2004, 76, 1967-1983. (h) Dalko, P.I.; Moisan, L. In the golden age of organocatalysis. Angew. Chem., Int. Ed., 2004, 43, 5138-5175. (i) Tietze, L.F.; Brasche, G.; Gericke, K. Domino Reactions in Organic Synthesis, Wiley-VCH: Weinheim, 2006. (j) Pellissier, H. Asymmetric domino reactions. Part B: Reactions based on the use of chiral catalysts and biocatalysts. Tetrahedron, 2006, 62, 2143-2173. (k) Pellissier, H. Asymmetric domino reactions. Part A: Reactions based on the use of chiral auxiliaries. Tetrahedron, 2006, 62, 1619-1665. (1) Padwa, A.; Bur, S.K. The domino way to heterocycles. Tetrahedron, 2007, 63, 5341-5378. (m) Enders, D.; Grondal, C.; Hüttl, M.R.M. Asymmetric organocalatylic domino reactions. Angew. Chem., Int. Ed., 2007, 46, 1570-1581. (n) Guillena, G.; Ramon, D.J.; Yus, M. Organocatalytic enantioselective multicomponent reactions (OEMCRs). Tetrahedron: Asymmetry, 2007, 18, 693-700. (o) D’Souza, D.M; Müller, T.J.J. Multi-component syntheses of heterocycles by transition-metal catalysis. Chem. Soc. Rev., 2007, 36, 1095-1108. (p) Nicolaou, K.C.; Chen, J.S. The art of total synthesis through cascade reactions. Chem. Soc. Rev., 2009, 38 , 2993-3009. (q) Touré, B.B.; Hall, D.G. Natural product synthesis using multicomponent reaction strategies. Chem. Rev., 2009, 109, 4439-4486. Special Issue on Rapid formation of molecular complexity in organic synthesis. Chem. Soc. Rev., 38(11), 2009, (r) Alba, A.N.; Companyo, X.; Viciano, M.; Rios, R. Organocatalytic domino reactions. Curr. Org. Chem., 2009, 13 1432-1474. (s) Grondal, C.; Jeanty, M.; Enders, D. Organocatalytic cascade reactions as a new tool in total synthesis. Nature Chemistry, 2010, 2, 167-178. (t) Ruiz, M.; Lopez-Alvarado, P.; Giorgi, G.; Menéndez, J.C. Domino reactions for the synthesis of bridged bicyclic frameworks: Fast access to bicyclo[n.3.1]alkanes. Chem. Soc. Rev., 2011, 40, 3445-3454. (u) Albrecht, L.; Jiang, H.; Jørgensen, K.A.A. Simple recipe for sophisticated cocktails: Organocatalytic One-Pot Reactions-concept, nomenclature, and future perspectives. Angew. Chem., Int. Ed., 2011, 50, 8492-8509. (v) Ruijter, E.; Scheffelaar, R.; Orru, R.V.A. Multicomponent reaction design in the quest for molecular complexity and diversity. Angew. Chem., Int. Ed., 2011, 50, 6234-6246. (w) Pellissier, H. Recent developments in asymmetric organocatalytic domino reactions. Adv. Synth. Catal., 2012, 354, 237-294. (x) De Graaff, C.; Ruijter, E.; Orru, R.V.A. Recent developments in asymmetric multicomponent reactions. Chem. Soc. Rev., 2012, 41, 3969-4009. (y) Pellissier, H. Asymmetric Domino Reactions, Royal Society of Chemistry: Cambridge, 2013. (z) Tietze, L.F. Domino Reactions-Concepts for Efficient Organic Synthesis, Wiley-VCH: Weinheim, 2014. (aa) Pellissier, H. Recent developments in enantioselective metal-catalyzed domino reactions. $A d v$ Synth. Catal., 2016, 72, 3133-3150.

[53] Pan, X.; Lu, C.; Nie, J.; Chen, Z.; Yang, G.; Dong, N.; Shi, J. Asymmetric domino Michael-aldol reactions catalyzed by recyclable PEG supported chiral primary aminoalcohol and primary-secondary diamine catalysts in water. Catal. Commun., 2014, 53, 72-76.

[54] Fukata, Y ; Okamura, T; Asano, K.; Matsubara, S. Asymmetric isomerization of $\omega$-Hydroxy- $\alpha, \beta$-unsaturated thioesters into $\beta$-Mercaptolactones by bifunctional aminothiourea catalyst. Org. Lett., 2014, 16, 2184-2187.

[55] Wang, J.; Yu, F.; Zhang, X.; Ma, D. Enantioselective assembly of substituted dihydropyrones via organocatalytic reaction in water media. Org. Lett., 2008 , 10,2561-2564.

[56] Huang, Y.C.; Uang, B.J. Remote sulfonamido group enhances reactivity and selectivity for asymmetric Michael Addition of nitroalkanes to $\alpha, \beta$ Unsaturated aldehydes. Chem. Asian J., 2014, 9, 2444-2448.

[57] Feng, J.; Li, X.; Cheng, J.P. Enantioselective organocatalyzed vinylogous Michael Reactions of 3-alkylidene oxindoles with enals. J. Org. Chem., 2017, 82, 1412-1419.

[58] Qiao, Y; Headley, A.D. A simple and highly effective water-compatible organocatalytic system for asymmetric direct Michael reactions of linear aldehydes to maleimides. Green Chem., 2013, 15, 2690-2694.

[59] Bradshaw, B.; Parra, C.; Bonjoch, J. Organocatalyzed asymmetric synthesis of morphans. Org. Lett., 2013, 15, 2458-2461.

[60] Bos, M.; Riguet, E. Synthesis of Chiral $\gamma$-Lactones by One-Pot sequential enantioselective organocatalytic Michael addition of boronic acids and diastereoselective intramolecular Passerini Reaction. J. Org. Chem., 2014, 79, 10881-10889. 
[61] (a) Pellissier, H. Chiral sulfur-containing ligands for asymmetric catalysis. Tetrahedron, 2007, 63, 1297-1330. (b) Mellah, M.; Voituriez, A.; Schulz, E. Chiral sulfur ligands for asymmetric catalysis. Chem. Rev., 2007, 107, 51335209. (c) Pellissier, H. Chiral Sulfur Ligands, Asymmetric Catalysis, Royal Society of Chemistry: Cambridge, 2009.

[62] Kalaria, P.N.; Avalani, J.R.; Raval, D.K. Highly enantioselective sulphaMichael addition to $\alpha, \beta$-unsaturated carbonyl scaffolds catalyzed by allyloxy-N-(1-benzyl) cinchonidinium bromide in water at room temperature. Tetrahedron: Asymmetry, 2016, 27, 947-953.

[63] Dong, N.; Zhang, Z.P.; Xue, X.S.; Li, X.; Cheng, J.P. Phosphoric acid catalyzed asymmetric 1,6-conjugate addition of thioacetic acid to paraquinone methides. Angew. Chem., Int. Ed., 2016, 55, 1460-1464.
[64] Chu, W.D.; Zhang, L.F.; Bao, X.; Zhao, X.H.; Zeng, C.; Du, J.Y.; Zhang, G.B.; Wang, F.X.; Ma, X.Y.; Fan, C.A. Asymmetric catalytic 1,6-conjugate addition/aromatization of para-quinone methides: Enantioselective introduction of functionalized diarylmethine stereogenic centers. Angew. Chem., Int. Ed., 2013, 52, 9229-9233.

[65] (a) Parra, A.; Tortosa, M. para-Quinone Methide: A new player in asymmetric catalysis. Chem CatChem, 2015, 7, 1524-1526. (b) Caruana, L. Fochi, M.; Bernardi, L. The emergence of quinone methides in asymmetric organocatalysis. Molecules, 2015, 20, 11733-11764.

[66] Akagawa, K.; Suzuki, R.; Kudo, K. Development of a peptide-based primary aminocatalyst with a helical structure. Asian J. Org. Chem., 2014, 3, 514522

DISCLAIMER: The above article has been published in Epub (ahead of print) on the basis of the materials provided by the author. The Editorial Department reserves the right to make minor modifications for further improvement of the manuscript. 